\title{
A Mechanism to Improve the Interpretability of Linguistic Fuzzy Systems with Adaptive Defuzzification based on the use of a Multi-objective Evolutionary Algorithm
}

\author{
Antonio A. Márquez, Francisco A. Márquez, Antonio Peregrín \\ Department of Information Technologies, University of Huelva \\ Huelva, 21819, Spain \\ E-mail: [amarquez, alfredo.marquez, peregrin]@dti.uhu.es \\ Received 15 December 2010 \\ Accepted 1 June 2011
}

\begin{abstract}
This paper proposes a mechanism that helps improve the interpretability of linguistic fuzzy ruled based systems with common adaptive defuzzification methods. Adaptive defuzzification significantly improves the system accuracy, but introduces weights associated with each rule of the rule base, decreasing the system interpretability. The suggested mechanism is based on three goals: 1) reducing the number of total rules considering that rule weight close to zero can be removed; 2) reducing the rules with weights coupled because rules with weights close to one do not need the weight, and 3) reducing rules triggered jointly, all of them by using several metrics and a proposed interpretability index. This is performed using a multi-objective evolutionary algorithm, obtaining a set of solutions with different trade-offs between accuracy and interpretability. In addition, it is important to note that adaptive defuzzification and therefore the proposal developed in this work can be used together with other methodologies to improve system interpretability and accuracy, so it can be viewed as an interesting component.
\end{abstract}

Keywords: Linguistic fuzzy modelling, interpretability-accuracy trade-off, multi-objective genetic algorithms, adaptive defuzzification methods.

\section{Introduction}

Fuzzy logic introduced by $\mathrm{Zadeh}^{1}$ is well-known by its suitability for linguistic concept modelling and its use in system identification. The semantic expressivity of fuzzy logic, using linguistic variables ${ }^{2}$ and linguistic rules $^{3}$, is quite close to expert natural language. Therefore, the use of fuzzy logic in system modelling favours the interpretability of the final model, at least from the structural transparency viewpoint. Fuzzy modelling ${ }^{4}$, i.e., system modelling with fuzzy rule base systems (FRBSs), is an important and active research line within the fuzzy logic community.

Accuracy and interpretability are in general terms contradictory goals: It is usually assumed that the more complex the FRBS is, the lower its interpretability, which means that complexity is implicitly considered to be related with a lack of interpretability. The ideal objective of fuzzy modelling would meet both criteria to a great extent, but the aforesaid opposition between both targets has shifted the problem to finding a balance between them ${ }^{5-13}$.

To summarize, two main trends are found regarding the improvement of the accuracy-interpretability tradeoff in the context of fuzzy systems ${ }^{5}$ :

- Linguistic fuzzy modelling (LFM), focused on the interpretability and then trying to improve the system accuracy ${ }^{6}$.

- Precise fuzzy modelling (PFM), which focuses on the accuracy and then attempts to achieve better system interpretability ${ }^{7}$.

A promising way is the LFM approach since it allows us to deal with the modelling of systems by building a linguistic model as starting point, which is clearly interpretable by humans. Concentrating then on LFM, historically at the researchers have usually initially focused on improving the accuracy of the models obtained without paying special attention to 
interpretability ${ }^{6,14-20}$. Nowadays, the interest of the researchers in interpretability has grown; they deal with improving the accuracy, trying to avoid decreases in interpretability of the system, and in general terms, looking for a good balance ${ }^{5,21-29}$ between both features.

Considering the interpretability and due to its subjective nature and the large amount of factors involved, the choice of appropriate measures is still an open problem ${ }^{21,28,30-34}$. In the specialist literature, there are proposal of different measures ${ }^{27,28,30-34}$ and techniques $^{8-10,22,23,35-37}$ for obtaining more interpretable linguistic fuzzy models. There are also different proposal for taxonomies ${ }^{30-33}$ to help better understand better the interpretability matter.

On the other hand, the adaptive inference system and especially the adaptive defuzzification methods have shown to be two important elements that could easily improve the accuracy of the system ${ }^{14-16}$. They are not the most relevant way to improve the accuracy, but they are well-matched with most other methodologies to do so. However, adaptive defuzzification methods introduce a loss of interpretability ${ }^{15,30-33}$, with implications for the overall meaning ${ }^{15,32}$.

Multi-objective evolutionary algorithms ${ }^{38,39}$ (MOEAs), have been shown to be a particularly interesting instrument to deal with the trade-off between accuracy and interpretability, due to the multi-objective nature of the problem ${ }^{21-25,35,40}$. They present in a single step a set of solutions with different equilibrium between the two contradictory features, letting the engineers select the most satisfactory for their purposes in each situation, which could also change, and it is not necessary to re-run the algorithm to seek another more appropriate solution.

Consequently, due to the interest of adaptive defuzzification methods from the point of view of accuracy, and bearing in mind their aforementioned drawback regarding interpretability issues, it was considered interesting to work on their accuracyinterpretability trade-off. To do so, this paper proposes to introduce a mechanism to improve the interpretability when using adaptive defuzzification method that reduces the number of global rules of the FRBS, decreases the number of rules with an associated weight and also reduces the number of rules triggered simultaneously. A MOEA is used to obtain a set of linguistic fuzzy models more interpretable than usual with adaptive defuzzification and still accurate by using both objectives related with interpretability and accuracy through several measures and a specifically designed interpretability index.

The paper is structured as follows: in section 2 we review the state of the art of the use of MOEA in interpretable linguistic FRBS modelling, and a description of adaptive defuzzification methods, their components, effects and recent works related on their interpretability. Section 3 begins with the description of the foundations of the mechanism proposed to improve the interpretability, and later shows two multi-objective models. In Section 4, two experimental studies are carried out to show the usefulness of the two models on thirteen real world problems. Finally, section 5 presents the conclusions of the studies performed.

\section{Preliminaries}

This section helps situate the presented work in the framework of the FRBS, and particularly with the previous works on the main streams found in the literature about two points: the use of MOEA in the trade-off between accuracy and interpretability, and the adaptive defuzzification methods and their issues in interpretability. We have not included preliminaries on interpretability here because they can be found in Refs. 30,31 and 33 , so we encourage the reader to review them if needed.

\subsection{Accuracy-interpretability trade-off and MOEAs}

As commented in the Introduction section, since accuracy and interpretability are conflicting goals, the use of evolutionary multi-objective ${ }^{38,39}$ strategies to find some points of equilibrium between the two features has become very popular in the linguistic FRBSs modelling field $^{21}$. This subsection is devoted to a review of some important works from the literature on MOEAs in the FRBS regarding the trade-off between interpretability and accuracy, following a line based on concepts together with historical evolution.

Ishibuchi has carried out some research on the application of MOEAs to the linguistic FRBS design, applied to classification problems. His earlier works ${ }^{9}$ were devoted to using simple first-generation MOEAs to perform a rule selection on an initial set of classification rules involving "don't care" conditions and considering two different objectives: classification accuracy and number of rules. The two-objective 
formulation in Ref. 9 was extended to three objectives in Ref. 41 by introducing the total number of antecedent conditions (i.e., the total rule length) as an additional complexity measure. A more effective MOEA, i.e., the multi-objective genetic local search (MOGLS) was used for three-objective genetic fuzzy rule selection in Ref. 42. An additional interesting study on the use of several multi-objective strategies in classification problems was discussed in Ref. 24.

Another contribution in this framework previously commented, and also applied to classification problems, is on Ref. 43, where Cordon et al. use a classical MOEA, (MOGA), to perform feature selection and fuzzy set granularity learning jointly with only two objectives.

On the other hand, there are only a few works in the framework of fuzzy modelling for regression problems. Next, we highlight some of the most significant papers on regression and MOEAs.

Ishibuchi in Ref. 44 show how a simple MOEA can be, applied to a three-objective optimization problem to obtain Mamdani FRBSs for regression problems.

Another interesting study is described in Ref. 29 where the authors present an adaptation of the efficient $(2+2)$ PAES for the identification of Mamdani FRBSs for regression problems by considering the minimization of two objectives (the system error and number of variables involved in the antecedents of the rules).

Later, some papers considered the use of MOEAs for learning or tuning of membership functions for regression problems. Thus, in Ref. 22 the authors used MOEAs in order to improve the fuzzy model accuracy while keeping its interpretability regarding both membership functions and fuzzy rules. Furthermore, the authors of Ref. 23 used MOEAS and a process for rule reduction jointly with a novel approach consisting of considering a new linguistic rule representation model based on the linguistic 2-tuples representation to perform a genetic lateral tuning of membership functions $^{35}$. Moreover, in Ref. 27, another MOEA has been adopted to perform context adaptation (adaptation of the membership functions by using scaling functions) as a post-processing algorithm applied to an initial knowledge base.

Recently, Ref. 25 has used a MOEA for granularity, membership function and rule learning. Furthermore, Ref. 40 improves the fuzzy model accuracy preserving the interpretability promoting the cooperation between fuzzy operators and rule base, also based on multiobjective strategies.

Notice that usually only two objectives are considered in the majority of the works. One of these usually concerns the accuracy which can easily be defined by checking how similar the outputs of the model and the real system are, for instance using the mean squared error. Nevertheless, some problems arise to characterize the second objective, interpretability, which is still an open problem.

\subsection{Adaptive defuzzification methods}

This subsection concisely revises the fundamentals of the main adaptive defuzzification methods used on fuzzy modelling.

Following the studies developed in Ref. 15, most adaptive defuzzification methods follow the expression (1),

$$
y_{0}=\frac{\sum_{i}^{N} f\left(h_{i}\right) \cdot V_{i}}{\sum_{i}^{N} f\left(h_{i}\right)}
$$

where $h_{i}$ is the matching degree between the input variables and the rule antecedent fuzzy sets, so $f\left(h_{i}\right)$ is a functional of matching degree, and $V_{i}$ represents a characteristic value of the fuzzy set inferred from rule $\mathrm{R}_{\mathrm{i}}$, the Maximum Value (MV) or the Centre of Gravity (CG). As shown, it is an expression of defuzzification method acting in Mode B, i.e. it defuzzifies first the individual contribution of each rule and then the final result is computed utilizing a weighted sum.

The functional term can take different arrangements, but the most frequent is the product: $\mathrm{f}\left(\mathrm{h}_{\mathrm{i}}\right)=\mathrm{h}_{\mathrm{i}} \cdot \alpha_{\mathrm{i}}$, where $\alpha_{\mathrm{i}}$ corresponds to a parameter for each rule $R_{i}, \mathrm{i}=$ 1 to $\mathrm{N}$, as well as the Centre of Gravity (CG) as characteristic value, due to its computational efficiency, linearity and similar results to other options for the functional term ${ }^{15}$. The final expression of the adaptive defuzzification method used in this paper is shown in (2).

$$
y_{0}=\frac{\sum_{i}^{N} h_{i} \cdot \alpha_{i} \cdot C G_{i}}{\sum_{i}^{N} h_{i} \cdot \alpha_{i}}
$$

The effect of $\alpha_{\mathrm{i}}$ zone is as follows:

$$
\alpha_{i} \cdot h_{i}, \alpha \in[1, \infty) \text { :empowerment of } h_{i},
$$




$$
\alpha_{i} \cdot h_{i}, \alpha \in[0,1] \text { : penalty of } h_{i} .
$$

In practice, the interval for $\alpha_{i}$ used is usually restricted to $[0,1]$ in order to act only as a penalty in different levels, obtaining similar results.

The product functional term, which employs a different parameter for each rule, has an effect similar to weighted rules ${ }^{45}$. The following is an example of a set of weighted rules, where the weights are $\alpha_{i}$ :

$$
\begin{aligned}
& R_{1} \text { : If } X_{11} \text { is } A_{11} \text { and } \ldots \text { and } X_{1 m} \text { is } A_{1 m} \text { then } Y \text { is } B_{1} \text { with } \alpha_{1} \\
& R_{2} \text { : If } X_{21} \text { is } A_{21} \text { and } \ldots \text { and } X_{2 m} \text { is } A_{2 m} \text { then } Y \text { is } B_{2} \text { with } \alpha_{2} \\
& R_{n} \text { : If } X_{n 1} \text { is } A_{n 1} \text { and } \ldots \text { and } X_{n m} \text { is } A_{n m} \text { then } Y \text { is } B_{n} \text { with } \alpha_{n}
\end{aligned}
$$

The $\alpha_{\mathrm{i}}$ values associated with rule $R_{i}$ acquires the meaning of how significant or important that rule is for the inference process.

The result of the use of rule weights in system modelling is a significant improvement of accuracy ${ }^{15}$. The rule weight adaptation is carried out frequently by using an evolutionary algorithm. The process of adaptation also produces a rule subset with better cooperation among the rules composing it ${ }^{15}$, due to rules with high level of cooperation among them get high values of weights and on the contrary, the rest of the rules obtain values close to zero.

From the point of view of the influence of adaptive defuzzification on the interpretability of fuzzy systems, this is an issue occasionally discussed. On one hand, Nauck and Kruse ${ }^{46}$ consider that rule weights could be equivalently replaced by modifications in the membership functions in the antecedents or consequents part, and they consider this a severe negative aspect in the semantic interpretability of the FRBSs.

Nevertheless, on the other hand, Ishibuchi and later Nakashima analysed the importance of weights viewed as certainty grades ${ }^{47}$. They showed that compact FRBSs can be designed without adjusting membership functions and can be partially replaced by the adjustment of the aforementioned certainty grades. They consider that the comprehensibility of the model viewing weights as certainty grades is not deteriorated significantly. In this way, the rule weight can be interpreted as the strength of each rule. They show that the larger the rule weight is, the large the decision area of each rule is. This approach allows a better approximation of interpretability working with rule weights because it retains the linguistic meaning of the data base.

\section{A new Proposal to Improve the Interpretability of Adaptive Defuzzification}

This section provides a detailed description of the mechanism to achieve interpretability improvements for FRBSs with adaptive defuzzification methods.

We begin by describing the mechanism, its metrics and interpretability indexes to set up a basic model and later, in subsection 3.2, an improved adaptive model also based on the same principles.

\subsection{Description of the proposed mechanism}

In this subsection, we shall describe the elements of the mechanism to improve the interpretability and several metrics to measure it when an adaptive defuzzification method is used in a linguistic FRBS.

The necessary reduction of rules with weight from the adaptive defuzzification ${ }^{30-33,45}$, the importance of rule selection ${ }^{8-12,42,44,48}$ and the interest in the reduction of rules triggered together ${ }^{49}$, all in order to reduce the system complexity and favour the compactness of the rule base, are the lines followed in our proposal.

\subsubsection{Mechanism and metrics}

We first describe the two threshold mechanisms, and then the reduction of rules with weight and rules triggered together.

\section{A. Mechanism of global rule selection based on a low threshold}

As mentioned in subsection 2.2, adaptive defuzzification methods are equivalent to using rules with weights. Therefore, rules with weights close to zero are those with the lowest influence on the final output. Hence, we propose avoiding the use of rules with the lowest weight values, removing those rules during the learning process of the weights. In this way, the effect of their contribution, even though it is small, is taken into account for the rest of the system.

This idea is applied establishing a threshold, $\mathrm{T}_{\mathrm{L}}$ (threshold low) that defines the cut-off level to remove rules. In order to measure its effect, we propose to use the usual metric:

- Number of final rules, $\left(\# R_{F}\right)$

Its expression is:

Minimize $\# R_{F}=\# R-\#\left(\right.$ rules with weights under $\left.T_{L}\right)$ 
with $\# \mathrm{R}$ as the number of rules of the rule base (initially), before starting the defuzzification parameter learning process, and \#(rules with weights under $T_{L}$ ) the number of rules whose weight is close to zero.

The rule selection improves the system interpretability, because the high-level interpretability ${ }^{31}$ and complexity of the system at rule base level ${ }^{33}$ are then improved. The description interpretability, a concept introduced in Ref. 32 regarding the system structure readability, is enhanced.

Rule selection can also enhance the system accuracy $^{8-11,23,34}$ because it improves the cooperation between the rules of the rule base.

\section{B. Mechanism to reduce the number of rules with weights based on a high threshold}

Weight values close to one belong to the most important rules for the FRBS. For this reason, we consider that these rules could be used without weights, and so we propose removing theses values during the learning process of the defuzzification parameters by using a new second threshold, $\mathrm{T}_{\mathrm{H}}$ (threshold high). The simply metric proposed to connect with this concept is the following:

- Number of rules with weight, $\left(\# R_{W}\right)$

It measures the number of rules with a weight associated of the rule base. Its expression is as follows:

Minimize $\# R_{W}=\# R$ - \#(rules with weights above $\left.T_{H}\right)(5)$

with \#R being the initial number of rules of the rule base, and \#(rules with weights above $T_{H}$ ) the number of rules whose weight is close to one.

This technique reduces the complexity, lessens the impact on the semantic interpretability of the adaptive defuzzification $^{46,33}$ and improves the explanation interpretability $^{32}$ which is related with the systems' comprehension of the model.

\section{Mechanism to reduce the average number of rules triggered together:}

Despite the fact that FRBSs obtain the output by combining the contribution of several rules triggered together with different levels, the system is more interpretable the lower the number of them triggered at the same time is ${ }^{49}$.

To take this fact into account, we shall use the following metric:
- Average number of rules triggered by each example, $\left(A v R_{T G}\right)$

Its expression is the following:

$$
\text { Minimize } A v R_{T G}=\frac{\sum_{j}^{M} R_{T G}^{j}}{P}
$$

where $P$ is the number of examples and $\# R_{T G}^{j}$ is the number of rules triggered by the example $\mathrm{j}$.

Thus, reducing $\mathrm{AvR}_{\mathrm{TG}}$, the rule base level ${ }^{31}$ and the semantic interpreatability ${ }^{33}$ are enhanced, as well as the explanation interpretability ${ }^{32}$.

\subsubsection{An interpretability index}

In the present work, we propose the aggregation of two metrics, $\# R_{W}$ and $A v R_{T G}$, in a global index based on the arithmetic mean of them, which is denoted as $\mathrm{R}_{\mathrm{W} \_} \mathrm{AvR}_{\mathrm{TG}}$.

To calculate the final expression of the new index (7), we first normalize both metrics to the range of 0 to 1 . Then, the value of $R_{W_{-}} A v R_{T G}$ ranges between 0 (the highest level of interpretability) and 1 (the lowest).

$$
\text { Minimize } \quad R_{W} A v R_{T G}=\frac{\# R_{W}+A v R_{T G}}{2}
$$

The interpretability index defined is based on two metrics which perform in the semantic ${ }^{33}$ and explanation $^{32}$ interpretability as was commented in subsection 3.1.1 when they were introduced. The minimization of this index recovers the interpretability lost due to by the effect of the adaptive defuzzification, while enhancing that of the global system, which could have a margin of improvement due to the learning effect or optimization of the knowledge base.

\subsection{Evolutionary multi-objective models proposed}

This subsection describes the two evolutionary models proposed that use a multi-objective algorithm with the mechanism to improve the interpretability for adaptive defuzzification systems described in the previous subsection.

\subsubsection{A first model: Fixed Thresholds}

The first model presented learns the parameters of the adaptive defuzzification, using the interpretability improvement mechanism described above with fixed 
thresholds and optimizing several objectives based on the metrics and index previously cited.

\section{The MOEA}

In this paper, an evolutionary model based on the popular NSGA-II ${ }^{50}$ was used. In the following, we state its main components and parameters.

\section{Objectives}

In a previous work ${ }^{51}$, we used the minimization of the $\# R_{F}$ and $R_{W_{-}} A v R_{T G}$ as an objective, but in the current study we only use the index $R_{W_{-}} A_{v} R_{T G}$. This is due to the fact that $\# \mathrm{R}_{\mathrm{F}}$ will be also minimized when minimizing the interpretability index, because it includes the $R_{W}$ and uses the $T_{L}$ mechanism to reduce the number of rules (section 3.1.1), so when minimizing the $R_{W}$ through the interpretability index, the $\# R_{F}$ will be also minimized.

Therefore, we will use the following two objectives:

- Interpretability maximization: Minimizing the index of interpretability, $\mathrm{R}_{\mathrm{W}_{-}} \mathrm{AvR}_{\mathrm{TG}}$.

- Accuracy maximization: Minimizing the classical Mean Square Error (MSE), defined in expression (8),

$$
\operatorname{MSE}(S)=\frac{\frac{1}{2} \sum_{k=1}^{P}\left(y_{k}-S\left(x_{k}\right)\right)^{2}}{P}
$$

where $S$ denotes the fuzzy model using the adaptive defuzzification method shown in expression (2), and the minimum t-norm as conjunction and inference operators. This measure uses a set of system evaluation data formed by $\mathrm{P}$ pairs of numerical data $Z_{k}=\left(x_{k}, y_{k}\right), k=1, . ., P$, with $x_{k}$ being the values of the input variables, and $y_{k}$ being the corresponding values of the associated output variables.

\section{Coding scheme and initial population}

We use a real coding scheme, where $n$ is the number of parameters $\alpha_{i}$ (of the adaptive defuzzification, one for each rule of the rule base $R_{i}$ ), whose values are within the interval $[0,1]$.

$$
\mathrm{C}=\left(\alpha_{1}, \ldots, \alpha_{\mathrm{n}}\right) \mid \alpha_{\mathrm{i}} \in\{0,1\}
$$

The initial population is set up as follows: An individual of the initial population has all the genes initially set to ' 1 ' in order to begin the evolutionary process with all the rules without weight. The remaining individuals of the initial population are set randomly.

\section{NSGA-II based multi-objective genetic algorithm}

NSGA-II ${ }^{50}$ is one of the most widely known and used second generation MOEA in the literature for solving multi-objective problems. It generates the offspring population from the current population through selection, crossover and mutation. It builds the next generation from the current population and the offspring until it reaches the stop condition, which in this work is based on the number of evaluations. The NSGA-II algorithm has two features that make it one of the main and most important MOEA: One is the assignment of fitness based on the Pareto ranking and crowding operator and the other is the procedure for updating each generation through elitism.

In this work, we have employed a MOEA based on the original NSGA-II with some adaptations. The proposed algorithm makes use of the NSGA-II selection mechanism, but in order to improve the search ability of the algorithm for our application, the searching effort is concentrated in a more interesting and reduced zone of the Pareto, the density of the obtained solutions being higher in this zone.

To do so, in each stage of the algorithm, we force the population to have a number of individuals dominated by error as a basis for the selection of the next generation, and make this number smaller as the algorithm progresses by reducing the number of required dominated solutions from $80 \%$ to $0 \%$ progressively with the generations, or what is the same, increasing the number of non-dominated solutions allowed from $20 \%$ to $100 \%$ gradually. Then, the solutions non-dominated are sorted from the best to the worst (considering accuracy as criterion).

\section{Important issues related with implementation}

This subsection raises two questions related with the implementation.

The first is related with the completeness ${ }^{52}$ of the rule bases obtained with this methodology; to ensure this property when removing rules from the rule base, we do not delete a rule if that rule is the only one to cover a specific example, since the effect on the FRBS is negative ${ }^{53,54}$.

The second issue is related with the implementation of the thresholds and the search ability of the 
mechanism: during the evolutionary process, the value of the chromosome could involve removing a rule, or eliminating the weight of a rule, but the original value is maintained within the chromosome in order to avoid affecting the crossover operator and evolutionary process.

\subsubsection{A Second Model: Adaptive Thresholds}

In this subsection, we propose a new approach based on the use of self-adapted thresholds instead of preset ones, in the same process of defuzzification parameters learning. In this way, the multi-objective learning process will obtain a set of FRBSs with different tradeoff between accuracy and interpretability by using not only the defuzzification parameters but also different thresholds.

\section{The adaptive thresholds mechanism}

We propose to adapt the available range for the adaptive defuzzification parameters using a single parameter $\beta_{\mathrm{T}}$ for the whole system, whose value is the width and is centred in the middle of the interval, as is shown in Figure 1. The use of a single parameter to carry out the adaptation of both thresholds, $\mathrm{T}_{\mathrm{H}}$ and $\mathrm{T}_{\mathrm{L}}$, jointly as proposed versus the use of two parameters representing the thresholds is less flexible, but reduces the search space of the evolutionary algorithm.

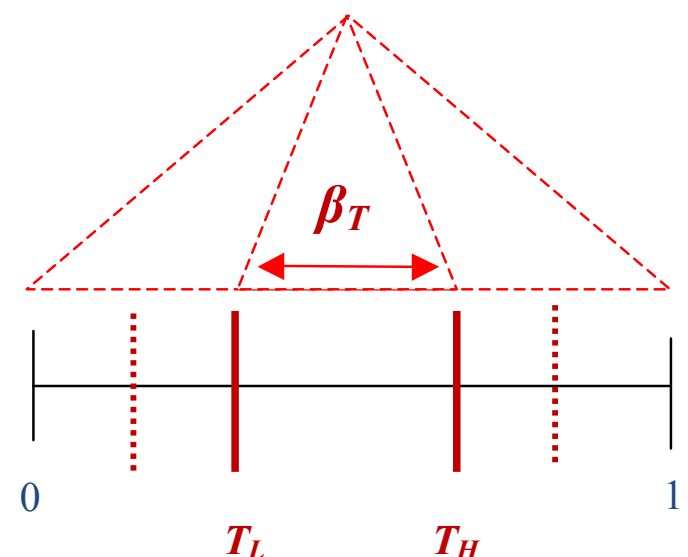

Fig. 1. Description or tne parameter to aaapt the thresholds

\section{The MOEA}

The new MOEAs have the same characteristics as the first proposal described. The difference is that this approach uses a double real coding scheme: the first part belongs to the parameters of the adaptive defuzzification $\left(\mathrm{C}_{\mathrm{D}}\right)$ and the second part is used for the parameter of the adaptive thresholds $\left(\mathrm{C}_{\mathrm{T}}\right)$. Then, the resulting chromosome is $\mathrm{C}=\mathrm{C}_{\mathrm{D}}+\mathrm{C}_{\mathrm{T}}$.

The new $\mathrm{C}_{\mathrm{T}}$ part is also real coded, and is composed of a single gene: $C_{T}=\beta_{T} \mid \beta_{T} \in[0.30,1]$. This interval lets the thresholds be between $\mathrm{T}_{\mathrm{L}}=0$ and $\mathrm{T}_{\mathrm{H}}=1$, and $\mathrm{T}_{\mathrm{L}}=0.35$ and $\mathrm{T}_{\mathrm{H}}=0.65$. It has been selected empirically performing different tests.

\section{Experimental Study}

To analyse the practical behaviour of the proposed methodology, an experimental study was carried out, divided into two parts. The first focused on the first model and the second on the adaptive thresholds model, with thirteen problems of varying complexities (different numbers of variables and available data). Table 1 summarizes the main characteristics of the thirteen datasets selected from the KEEL project ${ }^{55}$ webpage (http://www.keel.es) where they can be downloaded.

Table 1 Data sets considered for the experimental study

\begin{tabular}{lccc}
\hline \multicolumn{1}{c}{ Datasets } & Name & Variables & Patterns \\
\hline Plastic Strength & PLA & 3 & 1650 \\
Quake & QUA & 4 & 2178 \\
Electrical Maintenance & ELE & 5 & 1056 \\
AutoMPG6 & AU6 & 6 & 392 \\
AutoMPG8 & AU8 & 8 & 392 \\
Anacalt & ANA & 8 & 4052 \\
Abalone & ABA & 9 & 4177 \\
Concrete & CON & 9 & 1030 \\
Stock prices & STP & 10 & 950 \\
Ankara Weather & WAN & 10 & 1609 \\
Izmir Weather & WIZ & 10 & 1461 \\
Mortgage & MOR & 16 & 1409 \\
Treasure & TRE & 16 & 1409 \\
\hline
\end{tabular}

\subsection{Common set-up of experiments}

Two algorithms were used to obtain the initial set of candidate linguistic rules: the well-known ad-hoc datadriven algorithm of Wang and Mendel ${ }^{56}$ (WM) and the first stage of MOGUL-IRL ${ }^{52}$, which we name FS_MOGUL. No other methods from the literature were used, due to the problems they present when using a high number of variable datasets like the ones used in this work (see the lower zone of Table 1). In this paper, the linguistic partitions consist of five linguistic terms in 
the case of datasets with less than nine variables and three linguistic terms in the remaining ones (which helps to obtain a more reasonable and compact number of rules in the main datasets).

We adopted a 5-fold cross-validation model, i.e. 5 random partitions of the data each with $20 \%$ of the patterns of the data set, and used four folds for training and one for testing. For each of the data partitions, the learning methods were run 6 times using different seeds for the random number generator. For each data set, we therefore consider the average results of 30 runs.

The average results of the initial reference FRBSs obtained with WM and FS_MOGUL are shown in Tables 2 and 3.

Table 2 Initial Results using WM rule base

\begin{tabular}{cccc}
\hline Name & $\# \mathrm{R}$ & $\mathrm{MSE}_{\text {TRA }}$ & $\mathrm{MSE}_{\text {TST }}$ \\
\hline PLA & 14.80 & 3.434 & 3.557 \\
QUA & 53.60 & 0.0258 & 0.0267 \\
ELE & 65 & 56135 & 56359 \\
AU6 & 116.00 & 4.338 & 6.819 \\
AU8 & 70.60 & 12.71 & 13.73 \\
ANA & 72.40 & 0.187 & 0.189 \\
ABA & 68.20 & 8.407 & 8.424 \\
CON & 135.40 & 91.176 & 94.190 \\
STP & 122.80 & 9.074 & 9.042 \\
WAN & 156.00 & 16.063 & 16.403 \\
WIZ & 104.80 & 6.945 & 7.139 \\
MOR & 77.60 & 0.985 & 0.973 \\
TRE & 75.00 & 1.636 & 1.632 \\
\hline
\end{tabular}

Table 3 Initial Results using the first stage of FS_MOGUL rule base

\begin{tabular}{cccc}
\hline Name & \#R & MSE $_{\text {TRA }}$ & MSE $_{\text {TST }}$ \\
\hline PLA & 75.40 & 5.246 & 5.262 \\
QUA & 227.60 & 0.0633 & 0.0648 \\
ELE & 88.80 & 129400 & 133564 \\
AU6 & 170.60 & 8.565 & 13.154 \\
AU8 & 78.80 & 21.47 & 22.07 \\
ANA & 211.20 & 0.195 & 0.200 \\
ABA & 50.20 & 24.790 & 24.720 \\
CON & 124.40 & 163.157 & 164.638 \\
STP & 45.60 & 16.745 & 16.906 \\
WAN & 33.40 & 56.898 & 58.880 \\
WIZ & 52.40 & 38.414 & 41.442 \\
MOR & 31.40 & 2.002 & 1.995 \\
TRE & 33.00 & 2.667 & 2.685 \\
\hline
\end{tabular}

In the case of multi-objectives approaches, we adopt the use of the three representative points of the accuracy-interpretability objectives, as in Ref. 28 and 57: the most interpretable (MAX INT), the median (MEDIAN INT/ACC) and the most accurate in training
(MAX ACC) points. This methodology was used for two-objective problems in Ref. 57. Then, in Ref. 28, it was extended to problems with more than two objectives by projecting the obtained Pareto fronts in the planes generated by considering pairs of objectives. In this way, the non-dominated solutions can be analyzed by considering the aforesaid interesting points for each pair of objectives (each projected plane).

Therefore, for each representative point, we computed the mean values over the 30 trials of the MSEs on the training and test sets $\left(\mathrm{MSE}_{\mathrm{TRA}}\right.$ and $\mathrm{MSE}_{\mathrm{TST}}$ ), the $\# \mathrm{R}_{\mathrm{F}}$ (although it is not an objective of the MOEA) and $\mathrm{R}_{\mathrm{W} \_} \mathrm{AvR}_{\mathrm{TG}}$ index.

For the single-objective based approaches, we compute the same mean values over the 30 solutions obtained for each dataset. These three points are representative positions on the $\mathrm{MSE}-\mathrm{R}_{\mathrm{W}} \mathrm{AvR} \mathrm{R}_{\mathrm{TG}}$ plane, and were only considered in order to perform a statistical analysis. Anyway, the final user could select the most appropriate solution from the final Pareto front, by also looking for a trade-off between MSE, $\mathrm{R}_{\mathrm{F}}$ and $\mathrm{R}_{\mathrm{W} \_} \mathrm{AvR}_{\mathrm{TG}}$ depending on their own preferences.

In some cases, particularly with the second model, it was necessary to use another measure to capture the total MOEA performance ${ }^{38,58}$. We selected the Two Set Coverage $^{58}$ (CS) ratio as a tool to compare the Pareto fronts of different multi-objective approaches. CS considers $X^{\prime}, X^{\prime}, \subseteq X^{\prime}$ as two sets of phenotype decision vectors and a' and a', are two points belong to sets $X^{\prime}$ and $X^{\prime}$, respectively. CS is defined as the mapping of the order pair $\left(X^{\prime}, X^{\prime \prime}\right)$ to the interval $[0,1]$ per equation (9).

$$
C S\left(X^{\prime}, X^{\prime \prime}\right)=\frac{\mid\left\{a^{\prime \prime} \in X^{\prime \prime} ; \exists a^{\prime} \in X^{\prime}: a^{\prime} \geq a^{\prime \prime}\right\}}{\left|X^{\prime \prime}\right|},
$$

If all points in $X^{\prime}$ dominate or are equal to all points in $X^{\prime}$, , then by definition $C S=1$. $C S=0$ implies the opposite. In general $\mathrm{CS}\left(\mathrm{X}^{\prime}, \mathrm{X}^{\prime}\right)$ ) and $\mathrm{CS}\left(\mathrm{X}^{\prime}, \mathrm{X}^{\prime}\right)$, both have to be considered due to set intersection not being empty. The advantage of this metric is that it is easy to calculate and provides a relative comparison between MOEAS.

To assess whether there are significant differences among the results, we adopted statistical analysis ${ }^{59-62}$ and in particular non-parametric tests, according to the recommendations made in Ref. 61. In particular, for pair-wise comparison we use the Wilcoxon signed-rank test ${ }^{63,64}$, and for multiple comparison we shall employ 
different approaches, including Friedman's test ${ }^{65}$, to detect statistical differences among a group of results, and the Finner post-hoc test ${ }^{66}$ to observe the difference in performance between the methods and the retention or rejection of the hypothesis with the level of significance fixed. To perform the tests, we used a level of confidence $\alpha=0.05$. In particular, these tests are based on computing the differences on sample means (typically, mean test errors obtained by a pair of different algorithms on different datasets). In the classification framework, these differences are well defined since the errors are in the same domain. In the regression framework, to make the differences comparable, we adopt the normalized difference proposed in Ref. 57 and 28, namely DIFF and defined as:

$$
D I F F=\frac{\text { Mean }(\text { other })-\text { Mean }(\text { reference })}{\text { Mean }(\text { other })}
$$

where Mean(x) represents the MSE or $\# R_{F}$ (it is not necessary in the case of $\mathrm{R}_{\mathrm{W}_{-}} \mathrm{AvR}_{\mathrm{TG}}$ ) obtained by the $\mathrm{x}$ algorithm. This difference expresses the improvement percentage of the reference algorithm on the other one.

\subsection{First part of the experimental study}

In the first part of the experimental study we analyse the practical behaviour of the first model.

\section{A. Particular experimental set-up}

The FRBSs considered for this first part of the experimental study are summarized in Table 4, i.e. we are proposing the multi-objective approach with the interpretability improvement $\mathrm{MO}-\mathrm{AD}_{\mathrm{I}}$, but we also use two single-objective approaches: SO-AD which is the standard adaptive defuzzification ${ }^{15}$ accuracy oriented, and $\mathrm{SO}-\mathrm{AD}_{\mathrm{I}}$ which is the same, but adding the mechanisms proposed to improve the interpretability.

Table 4 Methods considered for comparison

\begin{tabular}{|c|c|}
\hline FRBSs & Description \\
\hline \multirow{3}{*}{$\begin{array}{l}S O-A D \\
S O-A D_{I}\end{array}$} & Single-Objective FRBSs \\
\hline & Adaptive Defuzzification ${ }^{15}$ \\
\hline & $\begin{array}{l}\text { Adaptive Defuzzification with the } \\
\text { mechanism to improve interpretability }\end{array}$ \\
\hline \multirow[b]{2}{*}{$M O-A D_{I}$} & Multi-Objective FRBSs \\
\hline & $\begin{array}{l}\text { Adaptive Defuzzification with the } \\
\text { mechanism to improve interpretability }\end{array}$ \\
\hline
\end{tabular}

Two different things will be studied in this first part of the experimental study: the influence of the values of the different thresholds for the interpretability improvement mechanism introduced first (subsection $\mathrm{B}$ ), and then we will compare the single and the multiobjective approaches (subsection C).

In the case of the studied adaptive defuzzification approaches, the values of the input parameters considered by the single-objective (SO-AD and SO$\mathrm{AD}_{\mathrm{I}}$ ) methods are: population size of 61,200000 evaluations, 0.6 as crossover probability and 0.2 as mutation probability per chromosome. In the case of the MOEAs, $\left(\mathrm{MO}-\mathrm{AD}_{\mathrm{I}}\right)$, they are: population size of 200 individuals, external population size of 200 individuals, 200000 evaluations, and 0.2 as mutation probability.

\section{B. Analysis of the influence of different values for the thresholds}

This section shows the results and analyses the proposed algorithm $\left(\mathrm{MO}-\mathrm{AD}_{\mathrm{I}}\right)$ to evaluate the behaviour of the different thresholds values. Therefore, we analyse the use of the multi-objective approach with different thresholds in order to study the influence of these values on the interpretability and accuracy criteria. To do this, we have chosen three fixed thresholds configurations:

- $\mathrm{T}_{\mathrm{L}}=0.1$ and $\mathrm{T}_{\mathrm{H}}=0.9$

- $\mathrm{T}_{\mathrm{L}}=0.2$ and $\mathrm{T}_{\mathrm{H}}=0.8$

- $\mathrm{T}_{\mathrm{L}}=0.3$ and $\mathrm{T}_{\mathrm{H}}=0.7$

Then, the multi-objective approaches were denoted by $\mathrm{MO}-\mathrm{AD}_{\mathrm{I}(0.1-0.9)}, \quad \mathrm{MO}-\mathrm{AD}_{\mathrm{I}(0.2-0.8)}, \quad \mathrm{MO}-\mathrm{AD}_{\mathrm{I}(0.3-0.7)}$, respectively.

Tables 5 and 6 show the three representative points for the different configurations (different thresholds, using the rule bases of WM and FS_MOGUL).

All the configurations have to be compared in order to determine which of them should be preferred. Since we will compare together more than two algorithms, on this occasion we use non-parametric tests for multiple comparisons. Particular details of the study can be consulted in Appendix A, where in order to perform a multiple comparison, it was necessary to check whether any of the results obtained by the algorithms presented any inequality. In the event of finding some, we can know by using a post-hoc test which algorithms partners' average results were dissimilar.

- Examining the results of the statistical analysis join to Tables 5 and 6 , we can conclude the following points: 
Table 5. Results obtained by MO-AD for different configurations of thresholds using the WM rule base

\begin{tabular}{|c|c|c|c|c|c|c|c|c|c|c|c|c|c|c|c|c|c|c|c|}
\hline \multirow[b]{2}{*}{ Dataset } & \multicolumn{8}{|c|}{ MAX $_{\text {INT }}$} & \multicolumn{4}{|c|}{ MEDIAN (INT/ACC) } & \multicolumn{7}{|c|}{ MAX $_{\mathrm{ACC}}$} \\
\hline & $\frac{\text { MO-AD }}{T_{L}-T_{H}}$ & - $\mathrm{MSE}_{t r a}$ & $\mathrm{MSE}_{t s t}$ & $\# \mathrm{R}_{\mathrm{F}}$ & $\mathrm{R}_{\mathrm{W}_{-}} \mathrm{Av \textrm {R } _ { \mathrm { TG } }}$ & $\left(\# \mathrm{R}_{\mathrm{w}}\right.$ & $\left.\mathrm{AvR}_{\mathrm{TG}}\right)$ & $\mathrm{MSE}_{t r a}$ & $\mathrm{MSE}_{t s t}$ & $\# \mathrm{R}_{\mathrm{F}}$ & $\mathrm{R}_{\mathrm{W}_{-}} \mathrm{AvR}_{\mathrm{TC}}$ & $\mathrm{G}\left(\# \mathrm{R}_{\mathrm{W}}\right.$ & $\left.\mathrm{AvR}_{\mathrm{TG}}\right)$ & $\mathrm{MSE}_{t r a}$ & $\mathrm{MSE}_{t s t}$ & $\# \mathrm{R}_{\mathrm{F}}$ & $\mathrm{R}_{\mathrm{W}_{-}} \mathrm{AvR}_{\mathrm{TC}}$ & $\left(\# \mathrm{R}_{\mathrm{w}} A\right.$ & $\left.\mathrm{AvR}_{\mathrm{TG}}\right)$ \\
\hline \multirow[t]{3}{*}{ PLA } & $0.1-0.9$ & 6.947800 & 6.940028 & 6.1 & 0.128 & $(0.00$ & $\begin{array}{ll}0 & 1.02)\end{array}$ & 2.073691 & 2.091053 & 10.6 & 0.385 & ( 2.23 & $\begin{array}{ll}3 & 2.48)\end{array}$ & 1.699226 & 1.759935 & 14.0 & 0.771 & $(10.80$ & $3.25)$ \\
\hline & $0.2-0.8$ & 7.042636 & 7.042633 & 6.0 & 0.125 & ( 0.00 & $\begin{array}{ll}0 & 1.00)\end{array}$ & 2.237865 & 2.245128 & 10.6 & 0.346 & ( 1.37 & $\begin{array}{ll}7 & 2.40)\end{array}$ & 1.769444 & 1.875019 & 13.9 & 0.675 & ( 8.50 & 3.11) \\
\hline & $0.3-0.7$ & 7.042636 & 7.042633 & 6.0 & 0.125 & ( 0.00 & $\begin{array}{ll}0 & 1.00)\end{array}$ & 2. & 5364 & 10.4 & & & $\begin{array}{ll}0 & 2.31)\end{array}$ & 1.830941 & 1.900387 & 12.4 & 0.551 & .13 & 2.75 ) \\
\hline \multirow[t]{3}{*}{ QUA } & $0.1-0.9$ & 0.023570 & 0.024276 & 22.7 & 0.179 & ( 4.93 & $\begin{array}{ll}3 & 2.12)\end{array}$ & 0.020914 & 0.022153 & 27.2 & 0.287 & (10.60 & $\begin{array}{ll}0 & 3.01)\end{array}$ & 0.020675 & 0.021944 & 32.6 & 0.448 & (22.67 & 3.79) \\
\hline & $0.2-0.8$ & 0.024555 & 0.025273 & 19.9 & 0.138 & ( 1.23 & $\begin{array}{ll}3 & 2.02)\end{array}$ & 0.021178 & 0.022430 & 25.6 & 0.237 & ( 6.67 & $\begin{array}{ll}7 & 2.80)\end{array}$ & 0.020782 & 0.022043 & 32.1 & 0.416 & (20.73 & $3.57)$ \\
\hline & 0.3 & 0.026361 & 0.027337 & 17.7 & 0.114 & $(0.13$ & $\begin{array}{ll}3 & 1.80)\end{array}$ & 0.021700 & 0.022975 & 24.7 & 0.193 & ( 3.13 & $\begin{array}{ll}3 & 2.62)\end{array}$ & 0.020897 & 0.022139 & 31.4 & 0.380 & $(17.37$ & 3.49) \\
\hline \multirow{3}{*}{ ELE } & $0.1-0.9$ & 57867 & 60608 & 35.8 & 0.167 & ( 7.37 & $\begin{array}{ll}7 & 3.10)\end{array}$ & 35428 & 39094 & 38.6 & 285 & $(16.30$ & $\begin{array}{ll}0 & 4.48)\end{array}$ & 32518 & 35633 & 45.2 & 0.469 & (33.27 & $5.96)$ \\
\hline & $0.2-0.8$ & 83303 & 84897 & 27.2 & 0.082 & ( 1.10 & $\begin{array}{ll}0 & 2.06)\end{array}$ & 44049 & 47997 & 34.0 & 0.159 & ( 6.30 & $\begin{array}{ll}0 & 3.11)\end{array}$ & 32947 & 35747 & 45.3 & 0.440 & $(29.23$ & (6.02) \\
\hline & $0.3-0.7$ & 143152 & 150408 & 20.0 & 0.063 & ( 0.03 & $\begin{array}{ll}3 & 1.77)\end{array}$ & 64459 & 70994 & 27.6 & 0.086 & ( 1.17 & $\begin{array}{ll}7 & 2.16)\end{array}$ & 33433 & 35677 & 45.4 & 0.421 & $(25.97$ & 6.19) \\
\hline \multirow[t]{3}{*}{ AU6 } & $0.1-0.9$ & 3.487613 & 6.568578 & 84.6 & 0.214 & ( 6.60 & $\begin{array}{ll}0 & 6.07)\end{array}$ & 2.746415 & 6.482094 & 73.4 & 0.293 & $(28.57$ & $\begin{array}{ll}7 & 5.57)\end{array}$ & 2.568845 & 6.457802 & 73.6 & 0.387 & $(48.77$ & 5.77) \\
\hline & $0.2-0.8$ & 3.715838 & 7.137473 & 61.2 & 0.143 & ( 2.77 & $\begin{array}{ll}7 & 4.29)\end{array}$ & 2.787005 & 6.521554 & 64.7 & 0.216 & (15.17 & 7 4.94) & 2.623889 & 6.440329 & 72.0 & 0.348 & $(41.27$ & $5.57)$ \\
\hline & $0.3-0.7$ & 5.551319 & 9.068401 & 40.9 & 0.086 & $(0.27$ & $\begin{array}{ll}7 & 2.78)\end{array}$ & 684 & 7.252765 & 52.2 & 32 & ( 3.43 & $\begin{array}{ll}3 & 3.84)\end{array}$ & 2.687347 & 6.430410 & 72.5 & .325 & $(35.53$ & $5.61)$ \\
\hline \multirow[t]{3}{*}{ AU8 } & $0.1-0.9$ & 11.281517 & 13.152617 & 32.1 & 0.132 & ( 3.00 & $\begin{array}{ll}0 & 3.93)\end{array}$ & 9.102294 & 11.28545 & 33.9 & 0.201 & $(10.80$ & $\begin{array}{ll}0 & 4.45)\end{array}$ & 8.897037 & 10.759520 & 36.2 & 0.303 & $(23.00$ & 4.99) \\
\hline & $0.2-0.8$ & 16.321254 & 18.062810 & 19.0 & 0.070 & ( 0.37 & $\begin{array}{ll}7 & 2.39)\end{array}$ & 9.601045 & 11.69286 & 26.3 & 124 & ( 3.80 & $\begin{array}{ll}0 & 3.47)\end{array}$ & 8.991249 & 10.937447 & 35.1 & 0.276 & (19.97 & $4.80)$ \\
\hline & $0.3-0.7$ & 21.088986 & 23.062541 & 14.8 & 0.054 & $(0.00$ & $\begin{array}{ll}0 & 1.93)\end{array}$ & 10.672853 & 12.84438 & 21.4 & 90 & ( 1.13 & $\begin{array}{ll}3 & 2.91)\end{array}$ & 9.127924 & 11.186454 & 35.9 & 0.255 & $(17.23$ & $4.73)$ \\
\hline \multirow[t]{3}{*}{ ANA } & $0.1-0.9$ & 0.647718 & 0.646577 & 63.7 & 0.190 & ( 1.77 & $\begin{array}{ll}7 & 1.43)\end{array}$ & 0.107990 & 0.109300 & 67.1 & 0.267 & ( 3.67 & $\begin{array}{ll}7 & 1.94)\end{array}$ & 0.007488 & 0.009588 & 67.5 & 0.659 & $(59.50$ & 1.98) \\
\hline & $0.2-0.8$ & 0.871531 & 0.871 & 54.9 & 51 & $(0.27$ & $\begin{array}{ll}7 & 1.19)\end{array}$ & 0. & 0.336884 & 60.4 & 16 & ( 1.27 & $\begin{array}{ll}7 & 1.65)\end{array}$ & 523 & 0.009669 & 65.6 & .585 & (48.97 & 7.97) \\
\hline & $0.3-0.7$ & 0.955815 & 0.96 & 45.6 & & ( 0.03 & $\begin{array}{ll}3 & 1.09)\end{array}$ & 22 & 663 & 50.6 & 95 & ( 0.70 & $\begin{array}{ll}0 & 1.52)\end{array}$ & 0.007551 & 0.009691 & 64.8 & 31 & 41.37 & $1.96)$ \\
\hline \multirow[t]{3}{*}{$\mathrm{ABA}$} & $0.1-0.9$ & 7.613683 & 7.712487 & 15.2 & 0.083 & ( 2.00 & $\begin{array}{ll}0 & 2.58)\end{array}$ & 4.836747 & 4.858605 & 19.8 & 0.142 & ( 6.23 & $\begin{array}{ll}3 & 3.66)\end{array}$ & 4.753375 & 4.789237 & 26.5 & 0.225 & (13.47 & 7.79) \\
\hline & $0.2-0.8$ & 12.693606 & 12.611176 & 11.2 & 0.050 & $(0.20$ & $\begin{array}{ll}0 & 1.85)\end{array}$ & 5.533293 & 5.538769 & 15.3 & 0.090 & ( 2.17 & $\begin{array}{ll}7 & 2.81)\end{array}$ & 4.790064 & 4.817361 & 25.9 & 0.213 & (12.17 & 4.73) \\
\hline & $0.3-0.7$ & 14.830294 & 14.893969 & 10.3 & 044 & ( 0.00 & $\begin{array}{ll}0 & 1.66)\end{array}$ & 6.432483 & 6.432756 & 13.4 & 666 & ( 0.37 & $\begin{array}{ll}7 & 2.42)\end{array}$ & & & 23.1 & .184 & ( 9.37 & 7.39) \\
\hline \multirow[t]{3}{*}{$\mathrm{CON}$} & $0.1-0.9$ & 70.753300 & 76.129910 & 83.8 & 0.131 & ( 6.30 & $\begin{array}{ll}0 & 10.97)\end{array}$ & 55.1029 & 61.1530 & 71.5 & 0.169 & $(20.23$ & $\begin{array}{ll}3 & 9.65)\end{array}$ & 50.3219 & 57.5966 & 59.9 & 0.219 & (37.07 & 8.39) \\
\hline & $0.2-0.8$ & 98.572969 & 4.99026 & 41.1 & .056 & ( 1.83 & $35.03)$ & 55.8998 & 64.5417 & 42.2 & 0.093 & ( 9.70 & $\begin{array}{ll}0 & 5.87)\end{array}$ & 51.4730 & 58.4786 & 56.0 & 0.190 & (30.87 & $7.70)$ \\
\hline & $0.3-0.7$ & 128.97494 & 134.53928 & 25.9 & 0.030 & $(0.03$ & $\begin{array}{ll}3 & 3.06)\end{array}$ & 73.2893 & 83.2969 & 33.2 & 0.049 & ( 1.60 & $\begin{array}{ll}0 & 4.37)\end{array}$ & 52.9665 & 59.9898 & 60.0 & 0.198 & $(31.23$ & $8.43)$ \\
\hline \multirow[t]{3}{*}{ STP } & & 3.708981 & 3.794866 & 25.7 & 0.061 & ( 3.20 & $\begin{array}{ll}0 & 5.04)\end{array}$ & 2.129880 & 2.227016 & 29.8 & 0.092 & ( 7.83 & $\begin{array}{ll}3 & 6.25)\end{array}$ & 2.052056 & 2.154450 & 36.7 & 0.139 & (15.43 & 7.94) \\
\hline & $0.2-0.8$ & 4.652642 & 4.674927 & 17.0 & 0.037 & $(0.60$ & $\begin{array}{ll}0 & 3.57)\end{array}$ & 2.321608 & 2.455662 & 23.8 & 0.064 & ( 3.83 & $\begin{array}{ll}3 & 5.06)\end{array}$ & 2.115639 & 2.209151 & 34.1 & 0.116 & $(11.53$ & 7.15 \\
\hline & $0.3-0.7$ & 8.3 & & 10.5 & 24 & ( 0.07 & $\begin{array}{ll}7 & 2.44)\end{array}$ & & 279 & 15.9 & & ( 1.13 & $\begin{array}{ll}3 & 3.58)\end{array}$ & & 2.2 & 33.8 & & ( 9.67 & 7.91) \\
\hline \multirow[t]{3}{*}{ WAN } & $0.1-0.9$ & 6.463753 & 7.172746 & 38.8 & 115 & $(12.30$ & $\begin{array}{ll}0 & 13.24)\end{array}$ & 6.033333 & 6.780082 & 43.1 & 0.146 & $(18.50$ & $\begin{array}{ll}0 & 15.22)\end{array}$ & 5.983361 & 6.674879 & 48.6 & 0.190 & $(27.90$ & $17.52)$ \\
\hline & $0.2-0.8$ & 9.346113 & 10.098808 & 31.0 & 0.060 & $(1.20$ & $\begin{array}{ll}0 & 9.81)\end{array}$ & 6.214014 & 6.936514 & 38.5 & 0.092 & ( 5.40 & $\begin{array}{ll}0 & 13.06)\end{array}$ & 6.040380 & 6.706163 & 46.7 & 0.159 & (19.83 & 16.73) \\
\hline & $0.3-0.7$ & 16.437768 & 17.227865 & 19.2 & 0.029 & $(0.03$ & $\begin{array}{ll}3 & 5.03)\end{array}$ & 7.376043 & 8.159211 & 27.6 & 0.052 & $(0.67$ & $\begin{array}{ll}7 & 8.66)\end{array}$ & 6.130478 & 6.859088 & 46.0 & 0.140 & $(14.50$ & $16.28)$ \\
\hline \multirow[t]{3}{*}{ WIZ } & $0.1-0.9$ & 3.846971 & 4.359892 & 30.5 & 0.147 & ( 7.90 & $\begin{array}{ll}0 & 10.00)\end{array}$ & 2.718277 & 3.149809 & 36.1 & 0.211 & (14.73 & $\begin{array}{ll}3 & 12.86)\end{array}$ & 2.629827 & 3.068601 & 43.2 & 0.297 & $(27.57$ & 15.13) \\
\hline & $0.2-0.8$ & 7.513500 & 8.062620 & 24.5 & 0.079 & $(0.87$ & $\begin{array}{ll}7 & 6.87)\end{array}$ & 3.009577 & 3.614640 & 32.7 & 0.146 & ( 5.47 & $\begin{array}{ll}7 & 11.02)\end{array}$ & 2.675106 & 3.230414 & 43.8 & 0.279 & $(23.43$ & $15.32)$ \\
\hline & $0.3-0.7$ & 24.7 & 25.488658 & 14.8 & & ( 0.03 & $3 \quad 3.11)$ & 5.940635 & & 19.3 & & ( 0.73 & $\begin{array}{ll}3 & 5.35)\end{array}$ & 2.734843 & 3.302554 & 45.1 & 0.265 & $(20.30$ & 15.39) \\
\hline \multirow[t]{3}{*}{ MOR } & $0.1-0.9$ & 1.590566 & 1.564395 & 9.2 & 0.042 & $(0.77$ & $\begin{array}{ll}7 & 2.97)\end{array}$ & 0.201851 & 0.219410 & 12.9 & 0.079 & ( 2.83 & $\begin{array}{ll}3 & 4.83)\end{array}$ & 0.153782 & 0.165901 & 16.5 & 0.144 & ( 9.57 & $6.50)$ \\
\hline & $0.2-0.8$ & 3.173316 & 3.214704 & 6.5 & 0.024 & $(0.13$ & $\begin{array}{ll}3 & 1.81)\end{array}$ & 0.321694 & 0.342161 & 10.6 & 0.053 & $(1.37$ & $\begin{array}{ll}7 & 3.54)\end{array}$ & 0.159248 & 0.171457 & 17.5 & 0.142 & ( 8.90 & 6.69) \\
\hline & & 3.180415 & 3.323322 & 5.6 & 0.021 & ( 0.00 & $\begin{array}{ll}0 & 1.64)\end{array}$ & 0.551852 & 0.574422 & 8.5 & 0.039 & ( 0.43 & $\begin{array}{ll}3 & 2.86)\end{array}$ & 0.163368 & 0.175955 & 18.2 & 0.137 & ( 7.90 & 6.86) \\
\hline \multirow[t]{3}{*}{ TRE } & $0.1-0.9$ & 1.720608 & 1.786207 & 10.3 & 0.045 & ( 0.67 & $\begin{array}{ll}7 & 2.96)\end{array}$ & 0.248659 & 0.280729 & 14.2 & 0.086 & ( 3.10 & $\begin{array}{ll}0 & 4.75)\end{array}$ & 0.202813 & 0.232601 & 20.3 & 0.177 & $(12.23$ & $7.00)$ \\
\hline & $0.2-0.8$ & 3.553366 & 3.630207 & 6.5 & 0.028 & $(0.00$ & $\begin{array}{ll}0 & 2.07)\end{array}$ & 0.557518 & 0.555809 & 10.7 & 0.056 & ( 1.00 & $\begin{array}{ll}0 & 3.61)\end{array}$ & 0.208263 & 0.237011 & 19.0 & 0.154 & ( 9.67 & $6.58)$ \\
\hline & $0.3-0.7$ & 4.611414 & 4.668308 & 5.5 & 0.025 & $(0.00$ & $\begin{array}{ll}0 & 1.80) \\
\end{array}$ & 1.005509 & 1.023034 & 7.9 & 0.039 & $(0.23$ & $\begin{array}{ll}3 & 2.72) \\
\end{array}$ & 0.212469 & 0.238197 & 18.9 & 0.144 & ( 7.93 & $6.68)$ \\
\hline
\end{tabular}

Published by Atlantis Press

Copyright: the authors

306 
Table 6. Results obtained by MO- $\mathrm{AD}_{\mathrm{I}}$ for different configurations of thresholds using the FS_MOGUL rule base

\begin{tabular}{|c|c|c|c|c|c|c|c|c|c|c|c|c|c|c|c|c|c|c|c|}
\hline \multirow[b]{2}{*}{ Dataset } & \multicolumn{8}{|c|}{$\mathrm{MAX}_{\mathrm{INT}}$} & \multicolumn{4}{|c|}{ MEDIAN (INT/ACC) } & \multicolumn{7}{|c|}{$\mathrm{MAX}_{\mathrm{ACC}}$} \\
\hline & $\frac{M O-A D_{I}}{T_{L}-T_{H}}$ & $\mathrm{MSE}_{t r a}$ & $\mathrm{MSE}_{t s t}$ & $\# \mathrm{R}_{\mathrm{F}}$ & $\mathrm{R}_{\mathrm{W}_{-}} \mathrm{AvR}_{\mathrm{TG}}$ & $\left(\# R_{W}\right.$ & $\left.\mathrm{AvR}_{\mathrm{TG}}\right)$ & $\mathrm{MSE}_{\text {tra }}$ & $\mathrm{MSE}_{t s t}$ & $\# \mathrm{R}_{\mathrm{F}}$ & $\mathrm{R}_{\mathrm{W}_{-}} \mathrm{AvR}_{\mathrm{TC}}$ & $\left(\# \mathrm{R}_{\mathrm{W}}\right.$ & $\left.\mathrm{AvR}_{\mathrm{TG}}\right)$ & $\mathrm{MSE}_{t r a}$ & $\mathrm{MSE}_{t s t}$ & $\# R_{F}$ & $\mathrm{R}_{\mathrm{W}_{-}} \mathrm{AvR} \mathrm{R}_{\mathrm{T}}$ & ( $\# \mathrm{R}_{\mathrm{u}}$ & $v R_{T}$ \\
\hline \multirow[t]{3}{*}{ PLA } & $0.1-0.9$ & 1.574572 & 1.623150 & 21.9 & 0.130 & ( 4.80 & $\begin{array}{ll}0 & 4.68)\end{array}$ & 1.171741 & 1.207446 & 29.3 & 0.216 & $(11.57$ & $\begin{array}{ll}7 & 6.61)\end{array}$ & 1.163733 & 1.201293 & 40.5 & 0.379 & $(28.03$ & 9.16) \\
\hline & $0.2-0.8$ & 3.278771 & 3.305375 & 11.5 & 0.051 & $(0.23$ & $\begin{array}{ll}3 & 2.37)\end{array}$ & 1.246104 & 1.273259 & 20.3 & 111 & ( 2.83 & $\begin{array}{ll}3 & 4.40)\end{array}$ & 1.164596 & 1.201882 & 36.9 & 0.298 & (19.17 & 8.12) \\
\hline & $0.3-0.7$ & 5.290166 & 5.346323 & 7.0 & 0.029 & $(0.00$ & $\begin{array}{ll}0 & 1.38)\end{array}$ & .754391 & 1.810790 & 13.2 & 663 & $(0.10$ & $\begin{array}{ll}0 & 2.97)\end{array}$ & 1.166274 & 1.204826 & 33.5 & 0.251 & (14.87 & 7.24) \\
\hline \multirow[t]{3}{*}{ QUA } & $0.1-0.9$ & 0.021684 & 0.022334 & 199.7 & 0.292 & $(13.63$ & 3 26.19) & 017291 & 018149 & 177.8 & 385 & (71.50 & (0 22.83) & 017111 & 018167 & 170.8 & 0.553 & $(141.50$ & 0 24.26) \\
\hline & $0.2-0.8$ & 0.017468 & 0.018472 & 132.1 & 0.208 & $(20.67$ & $\begin{array}{ll}7 & 16.32)\end{array}$ & .017125 & 0.018199 & 123.1 & 260 & $(43.27$ & 7 16.55) & 0.017071 & 0.018207 & 124.1 & 0.320 & $(65.73$ & 17.58) \\
\hline & $0.3-0.7$ & 0.017608 & 0.018610 & 86.4 & 0.129 & (13.13 & 3 10.08) & 0.017135 & 0.018257 & 98.0 & .174 & $(22.40$ & $\begin{array}{ll}0 & 12.52)\end{array}$ & 0.017088 & 0.018183 & 117.2 & 0.268 & $(48.00$ & 16.29) \\
\hline \multirow[t]{3}{*}{ ELE } & $0.1-0.9$ & 64241 & 67141 & 56.0 & 129 & ( 4.23 & $\begin{array}{ll}3 & 4.10)\end{array}$ & 42156 & 45526 & 49.5 & 228 & $(17.10$ & $\begin{array}{ll}0 & 5.09)\end{array}$ & 39495 & 42072 & 52.0 & 0.352 & $(33.80$ & $6.28)$ \\
\hline & $0.2-0.8$ & 84698 & 87379 & 35.9 & 0.068 & $(1.40$ & $\begin{array}{ll}0 & 2.35)\end{array}$ & 46395 & 50173 & 40.8 & 0.126 & ( 6.07 & $\begin{array}{ll}7 & 3.57)\end{array}$ & 39976 & 42689 & 49.6 & 297 & $(26.70$ & 5.68) \\
\hline & $0.3-0.7$ & 108723 & 113 & 23.2 & 048 & $(0.07$ & $\begin{array}{ll}7 & 1.85)\end{array}$ & 61099 & 5626 & 29.1 & 778 & ( 2.07 & $\begin{array}{ll}7 & 2.56)\end{array}$ & 40766 & 43063 & 48.5 & 258 & $(22.10$ & $5.18)$ \\
\hline \multirow[t]{3}{*}{ AU6 } & $0.1-0.9$ & 3.821884 & 6.76 & 143.4 & 197 & ( 4.50 & $\begin{array}{ll}0 & 10.80)\end{array}$ & 3.296278 & 516126 & 129.9 & 266 & (32.60 & $\begin{array}{ll}0 & 9.97)\end{array}$ & 543 & 263927 & 111.0 & 389 & 79.53 & 9.18) \\
\hline & $0.2-0.8$ & 3.454157 & 7.474670 & 79.4 & 0.133 & $(10.20$ & $\begin{array}{ll}0 & 6.07)\end{array}$ & 3.009759 & 6.955385 & 81.0 & 173 & $(21.03$ & $\begin{array}{ll}3 & 6.51)\end{array}$ & 925950 & 6.544321 & 86.8 & 0.235 & (38.40 & 7.15) \\
\hline & $0.3-0.7$ & 4.202431 & 7.836509 & 58.7 & 083 & ( 3.43 & $\begin{array}{ll}3 & 4.31)\end{array}$ & 3.124690 & 7.149861 & 69.9 & 126 & $(10.77$ & $\begin{array}{ll}7 & 5.52)\end{array}$ & .976153 & 6.502033 & 88.3 & 226 & (34.93 & 7.27) \\
\hline \multirow[t]{3}{*}{ AU8 } & $0.1-0.9$ & 10.610777 & 11.814385 & 24.6 & 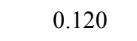 & ( 3.97 & $\begin{array}{ll}7 & 3.30)\end{array}$ & & 129575 & 27.7 & & (11.33 & $\begin{array}{ll}3 & 3.95)\end{array}$ & & 9.000788 & 33.3 & 283 & (22.67 & 4.81) \\
\hline & $0.2-0.8$ & 16.296509 & 18.007791 & 18.0 & 0.06 & 0.63 & $\begin{array}{ll}3 & 2.28)\end{array}$ & 8196 & .633468 & 23 & 122 & ( 4.43 & $\begin{array}{ll}3 & 3.28)\end{array}$ & 334 & 047838 & 31.6 & .250 & (18.63 & 4.57) \\
\hline & $0.3-0.7$ & 19.9 & 20.495670 & 14.7 & 556 & 0.00 & $\begin{array}{ll}0 & 2.00)\end{array}$ & 872984 & 3105 & 19.3 & 1 & ( 0.37 & $\begin{array}{ll}7 & 2.76)\end{array}$ & & 9.082736 & 32.1 & .238 & $(17.17$ & $4.52)$ \\
\hline \multirow[t]{3}{*}{ ANA } & $0.1-0.9$ & 0.044437 & 0.047909 & 174.4 & 88 & $(12.07$ & $\begin{array}{ll}7 & 4.67)\end{array}$ & 63 & 5529 & 154.4 & 250 & (44.00 & $\begin{array}{ll}0 & 4.24)\end{array}$ & 0.007158 & 335 & 133.0 & 358 & $(91.53$ & 4.12) \\
\hline & $0.2-0.8$ & 0.038210 & 0.040613 & 129.3 & 141 & $(12.93$ & $\begin{array}{ll}3 & 3.22)\end{array}$ & 0.009456 & 0.011776 & 114.0 & & $(27.63$ & 68) & 0.007033 & 009237 & 112.5 & 252 & (50.90 & 3.84) \\
\hline & $0.3-0.7$ & 0.12 & 0 & 85.7 & & ( 8.33 & $\begin{array}{ll}3 & 2.16)\end{array}$ & & 568 & 92.5 & & $(10.17$ & 93) & 180 & 461 & 108.3 & 216 & $(34.20$ & 3.92) \\
\hline \multirow[t]{3}{*}{ ABA } & $0.1-0.9$ & 10.034018 & 9.980401 & 15.6 & 0.098 & 1.10 & $\begin{array}{ll}0 & 2.33)\end{array}$ & 52071 & .261997 & 20. & 180 & ( 5.57 & 3.34) & 6.198179 & 6.219666 & 24.9 & 0.311 & $(15.07$ & 4.32) \\
\hline & $0.2-0.8$ & 13.518071 & 13.474387 & 10.1 & 064 & ( 0.03 & $\begin{array}{ll}3 & 1.70)\end{array}$ & 6.450398 & 6.484010 & 15.2 & 115 & ( 1.40 & $\begin{array}{ll}0 & 2.69)\end{array}$ & 6.200991 & 6.221171 & 24.6 & 0.258 & $(10.83$ & 4.02) \\
\hline & $0.3-0.7$ & 13.471095 & 13.490648 & 9.1 & 058 & ( 0.00 & $\begin{array}{ll}0 & 1.56)\end{array}$ & 6.933849 & 6.956984 & 13.8 & 999 & ( 0.70 & $\begin{array}{ll}0 & 2.45)\end{array}$ & 6.204145 & 6.222632 & 22.9 & 220 & ( 7.90 & 3.77) \\
\hline \multirow[t]{3}{*}{$\mathrm{CON}$} & $0.1-0.9$ & 67.672232 & 71.789422 & 86.8 & & ( 5.13 & 3 12.02) & 59.010937 & 65.03955 & 66.0 & 201 & $(25.23$ & 74) & .380503 & 62.489223 & 62.6 & 257 & (39.37 & 9.66) \\
\hline & $0.2-0.8$ & 80.29 & 88.380934 & 40.9 & 0 & ( 3.53 & $\begin{array}{ll}3 & 5.52)\end{array}$ & 58.3 & 65.72600 & 45.4 & & $(10.77$ & 37) & 133 & 62.796797 & 55.0 & 95 & $(27.00$ & 8.43) \\
\hline & -0.7 & 28 & 123.1 & 2 & & & $\begin{array}{ll}0 & 3.4\end{array}$ & 98 & 797 & 36. & & 67 & 44) & 287 & 5839 & 5 & 39 & $(24.53$ & $8.79)$ \\
\hline \multirow[t]{3}{*}{ STP } & $0.1-0.9$ & 5.405339 & 5.474713 & 13.3 & 096 & 1.33 & $\begin{array}{ll}3 & 3.21)\end{array}$ & 4.259753 & 4.362481 & 18.6 & 167 & ( 4.63 & $\begin{array}{ll}3 & 4.54)\end{array}$ & 4.159594 & 4.255350 & 25.0 & 0.287 & $(11.73$ & 6.19) \\
\hline & & 7.052710 & 7.174048 & 9.1 & 063 & ( 0.13 & $\begin{array}{ll}3 & 2.41)\end{array}$ & 4.338720 & 4.473762 & 16.2 & 136 & ( 3.17 & $\begin{array}{ll}7 & 3.98)\end{array}$ & 4.179792 & 4.288358 & 25.0 & 268 & ( 9.90 & $6.25)$ \\
\hline & $0.3-0.7$ & 8.748136 & & 7.9 & & $(0.00$ & $\left.\begin{array}{ll}0 & 2.25\end{array}\right)$ & & 4.560821 & 14.7 & & ( 2.67 & $\begin{array}{ll}7 & 3.75)\end{array}$ & & & & 52 & ( 8.50 & 6.22) \\
\hline \multirow[t]{3}{*}{ WAN } & $0.1-0.9$ & .310868 & & 9.6 & & 0.53 & & & & 13 & & ( & & & & & & & 6.19) \\
\hline & $0.2-0.8$ & .878818 & 30.684648 & 7.9 & 0 & 0.00 & $\begin{array}{ll}0 & 2.43)\end{array}$ & 15 & 337 & 12. & 150 & ( 2.43 & $\begin{array}{ll}3 & 4.00)\end{array}$ & 013 & 14.079000 & 15.6 & 331 & $(10.67$ & $5.96)$ \\
\hline & $0.3-0.7$ & .988571 & 34.115293 & 7.9 & & 10 & $\begin{array}{ll}0 & 2.2 \\
\end{array}$ & & & 1 & & ( 0.93 & 81) & & 7306 & 15.2 & 302 & ( 9.47 & 5.61) \\
\hline \multirow[t]{3}{*}{ WIZ } & $0.1-0.9$ & 12.545764 & 13.543774 & 15.7 & 107 & ( 2.57 & $\begin{array}{ll}7 & 4.18)\end{array}$ & 3.881428 & 4.467590 & 19.7 & 93 & ( 7.50 & $\begin{array}{ll}0 & 6.11)\end{array}$ & 413844 & 3.856717 & 25.0 & 351 & $(19.80$ & $8.12)$ \\
\hline & $0.2-0.8$ & 34.049969 & 35.694754 & 11.6 & 0.059 & ( 0.13 & $\begin{array}{ll}3 & 2.93)\end{array}$ & 4.965794 & 5.631655 & 16.9 & 21 & ( 2.30 & $\begin{array}{ll}0 & 5.01)\end{array}$ & & 2941 & 24.4 & 0.314 & $(16.77$ & 7.72) \\
\hline & $0.3-0.7$ & & & 1 & & & & & & 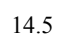 & & & & & & & & 4.73 & 7.61) \\
\hline \multirow[t]{3}{*}{ MOR } & $0.1-0.9$ & & & 6.0 & & & & & & 8. & & & & & & & 305 & .03 & $5.06)$ \\
\hline & $0.2-0.8$ & 3.325074 & 3.280224 & 5.6 & 0.055 & ( 0.00 & $\begin{array}{ll}0 & 1.74)\end{array}$ & 0.502724 & 0.495026 & 7.8 & 0.118 & $(1.90$ & $\begin{array}{ll}0 & 2.76)\end{array}$ & 0.275008 & 0.281564 & 13.0 & 0.302 & ( 8.77 & 5.12) \\
\hline & $0.3-0.7$ & 3.689980 & 3.747015 & 5.8 & 0.050 & ( 0.00 & $\begin{array}{ll}0 & 1.58)\end{array}$ & 0.548342 & 0.553402 & 7.8 & 0.109 & ( 1.50 & $\begin{array}{ll}0 & 2.69)\end{array}$ & 0.283597 & 0.290467 & 13.0 & 0.293 & ( 8.13 & $5.15)$ \\
\hline \multirow[t]{3}{*}{ TRE } & $0.1-0.9$ & 4.887197 & 5.066371 & 5.8 & 0.054 & ( 0.17 & $\begin{array}{ll}7 & 1.80)\end{array}$ & 0.806103 & 0.792245 & 8.7 & 0.104 & $(0.87$ & $\begin{array}{ll}7 & 3.17)\end{array}$ & 0.448043 & 0.436540 & 10.4 & 0.229 & ( 7.20 & 4.17) \\
\hline & $0.2-0.8$ & 5.307431 & 5.513163 & 5.4 & 0.048 & ( 0.00 & $\begin{array}{ll}0 & 1.67)\end{array}$ & 0.931746 & 0.905101 & 8.4 & 0.092 & ( 0.43 & $\begin{array}{ll}3 & 2.96)\end{array}$ & 0.450184 & 0.436108 & 10.3 & 0.218 & ( 6.60 & 4.10) \\
\hline & $0.3-0.7$ & 4.886871 & 4.991007 & 5.7 & 0.046 & ( 0.00 & $\begin{array}{ll}0 & 1.62)\end{array}$ & 0.991394 & 0.975439 & 8.0 & 0.084 & $(0.23$ & $\begin{array}{ll}3 \quad 2.81) \\
\end{array}$ & 0.455389 & 0.437021 & 10.3 & 0.211 & ( 6.17 & $4.10)$ \\
\hline
\end{tabular}

Published by Atlantis Press

Copyright: the authors 
1. The best interpretability is obtained with the thresholds $\mathrm{T}_{\mathrm{L}}=0.3$ and $\mathrm{T}_{\mathrm{H}}=0.7$ (interpretability index and metrics, are better with them) while the best accuracy is obtained with the thresholds $\mathrm{T}_{\mathrm{L}}=0.1$ and $\mathrm{T}_{\mathrm{H}}=0.9$. We think that this is because the more aggressive setup $\left(T_{L}=0.3\right.$ and $\left.T_{H}=0.7\right)$ lets the learning algorithm attack the interpretability index more strongly, reducing rules with weight and rules triggered together converging to zones with solutions more interpretable quickly. In contrast, the more conservative setup $\left(\mathrm{T}_{\mathrm{L}}=0.1\right.$ and $\mathrm{T}_{\mathrm{H}}=0.9$ ) forces the learning algorithm to search in a less interpretable zone, favouring easier convergence with the most accurate solutions. This is a coherent result because a $T_{H}$ of 0.7 considerably reduces the number of rules with weight, and a $T_{L}$ of 0.3 also reduces the number of rules powerfully, but there is a reduction in the range available for the rule weights from 0.3 to 0.7 , which is thinner than the range from 0.1 to 0.9 . Wider ranges of rule weights allow greater accuracy.

2. Results obtained in the most accurate point (MAX ACC) by the three thresholds are similar regarding accuracy. As commented before, they are better with $T_{L}=0.1$ and $T_{H}=0.9$ but when using the other two thresholds setups, the accuracy is not strongly harmed while the interpretability is enhanced more substantially, e.g. the number of rules with weight is about the half of the total number of rules.

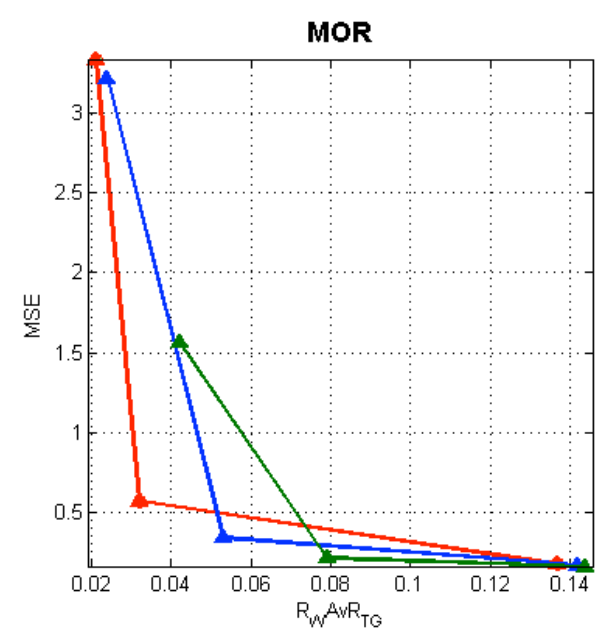

Finally, Figure 2 shows the comparison between the Pareto fronts obtained with different thresholds, on this occasion from FRBSs obtained using the WM rule base, and particularly for the MOR and STO problems, as an example. Results are extensive to the rest of the datasets and FRBSs that use FS_MOGUL rule bases. We plotted the three points, the MAX INT, the MEDIAN (INT/ACC) and the MAX ACC for each MOEA. The approximations of the Pareto fronts achieved by $\mathrm{T}_{\mathrm{L}}=0.1$ and $\mathrm{T}_{\mathrm{H}}=0.9$ are in general more accurate than the Pareto fronts obtained by $\mathrm{T}_{\mathrm{L}}=0.3$ and $\mathrm{T}_{\mathrm{H}}=0.7$ which are more interpretable, as was expected. Moreover, it can be observed that the Pareto fronts obtained by $\mathrm{MO}-\mathrm{AD}_{\mathrm{I}(0.3-}$ 0.7) are wider than those obtained with $\mathrm{MO}-\mathrm{AD}_{\mathrm{I}(0.1-0.9)}$. It is coherent with the second main previous result obtained studying the tables: the best accuracies are reached by the MO- $\mathrm{AD}_{\mathrm{I}(0.1-0.9)}$ models, but $\mathrm{MO}-\mathrm{AD}_{\mathrm{I}(0.3-}$ 0.7) are close to them in accuracy (MAX ACC), and also reach the greatest level in accuracy (MAX INT).

\section{Comparing the proposals against single- objective approaches}

This subsection analyses the performance of our multi-objective proposal against the single-objective approach.

We selected the set-up $\mathrm{T}_{\mathrm{L}}=0.1$ and $\mathrm{T}_{\mathrm{H}}=0.9$ because, as shown before, it has achieved the best results in accuracy, and the single-objective approaches also use a single-objective based on accuracy.

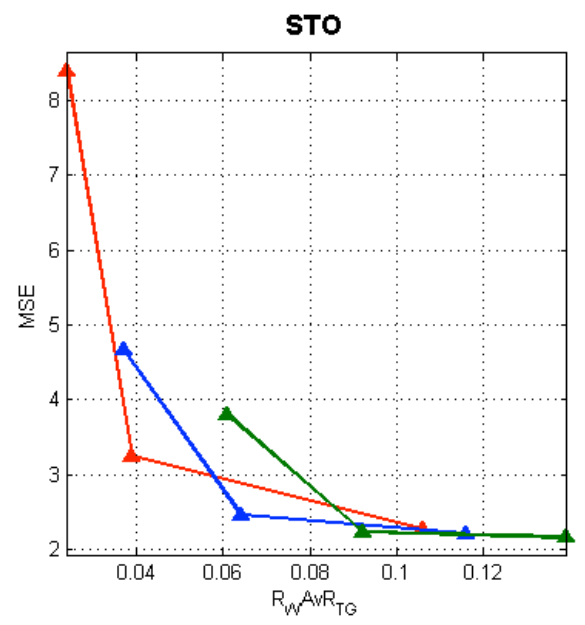

Fig. 2. Average Pareto fronts obtained for STO and MOR problems in the accurate-interpretability plane for WM. 
Clearly it would make no sense to consider the interpretability index in the single-objective accuracy oriented, because this index affects the interpretability and the objective employed is accuracy only (assuming that accuracy oriented approaches have the worst values for $\mathrm{R}_{\mathrm{W}} \mathrm{AvR}_{\mathrm{TG}}$ ). However, with the aim of comparing the most accurate point in multi-objective approach with the single-objective approach, we also introduced these indexes in the single-objective approach $\left(\mathrm{SO}_{-} \mathrm{AD}_{\mathrm{I}}\right)$ in order to see how the accuracy of the index was affected.
Table 7 shows the result of the single-objective approaches, where SO-AD is the single-objective with adaptive defuzzification and $\mathrm{SO}-\mathrm{AD}_{\mathrm{I}(0.1-0.9)}$ is the singleobjective approach with the mechanism to improve the interpretability, together with the results of the multiobjective approach MO-AD $\mathrm{I}(0.1-0.9)_{\text {for }}$ for most accurate point from Table 5 and 6 .

To compare the multi-objective approach against the single-objective ones, we performed a statistical analysis in the different measures to check if there are

Table 7 Results obtained by standard single-objectives models accuracy oriented (SO-AD) vs single-objectives models with the interpretability improvement mechanism $\left(\mathrm{SO}-\mathrm{AD}_{\mathrm{I}(0.1-0.9)}\right)$, and multi-objective models proposal $\left(\mathrm{MO}-\mathrm{AD}_{\mathrm{I}(0.1-0.9)}\right)$, with both, $\mathrm{WM}$ and FS_MOGUL rule bases

\begin{tabular}{|c|c|c|c|c|c|c|c|c|c|c|c|c|c|}
\hline \multirow[b]{2}{*}{ Dataset } & \multirow[b]{2}{*}{ FRBSs } & \multicolumn{6}{|c|}{ WM } & \multicolumn{6}{|c|}{ FS_MOGUL } \\
\hline & & $\mathrm{MSE}_{t r a}$ & $\mathrm{MSE}_{t s t}$ & $\# \mathrm{R}_{\mathrm{F}}$ & $\mathrm{R}_{\mathrm{w}_{-}} \mathrm{AvR}$ & $\mathrm{R}_{\mathrm{TG}}\left(\# \mathrm{R}_{\mathrm{W}}\right.$ & $\left.\mathrm{AvR}_{\mathrm{T}}\right)$ & $\mathrm{MSE}_{\text {tra }}$ & $\mathrm{MSE}_{t s t}$ & $\# \mathrm{R}_{\mathrm{F}}$ & $\mathrm{R}_{\mathrm{W}_{-}} \mathrm{AvF}$ & $\mathrm{T}_{\mathrm{TG}}\left(\# \mathrm{R}_{\mathrm{W}}\right.$ & $\left.\mathrm{AvR}_{\mathrm{T}}\right)$ \\
\hline \multirow{3}{*}{ PLA } & SO-AD & 1.694533 & 1.749531 & 14.80 & 0.913 & $(14.80$ & $3.30)$ & 1.274698 & 1.295137 & 75.40 & 0.904 & $(75.40$ & 19.25) \\
\hline & SO-AD & 1.705751 & 1.765311 & 14.33 & 0.813 & (11.97 & $3.27)$ & 1.252672 & 1.269589 & 58.97 & 0.645 & $(52.83$ & 14.02) \\
\hline & MO-AD & 1.699226 & 1.759935 & 14.0 & 0.771 & $(10.80$ & $3.25)$ & 1.163733 & 1.201293 & 40.5 & 0.379 & $(28.03$ & $9.16)$ \\
\hline \multirow[t]{3}{*}{ QUA } & SO-AD & 0.021303 & 0.022412 & 53.60 & 0.892 & $(53.60$ & $6.27)$ & 0.017394 & 0.018187 & 227.60 & 0.829 & $(227.60$ & $32.89)$ \\
\hline & SO-AD & 0.021163 & 0.022351 & 42.40 & 0.633 & $(38.17$ & 4.43) & 0.017366 & 0.018170 & 205.97 & 0.720 & (197.87 & $28.48)$ \\
\hline & $\mathrm{MO}-\mathrm{AD}_{\mathrm{I}}$ & 0.020675 & 0.021944 & 32.6 & 0.448 & $(22.67$ & $3.79)$ & 0.017111 & 0.018167 & 170.8 & 0.553 & $(141.50$ & $24.26)$ \\
\hline \multirow[t]{3}{*}{ ELE } & SO-AD & 36455 & 38917 & 65.00 & 0.880 & $(65.00$ & 10.66) & 43517 & 47035 & 88.80 & 0.759 & $(88.80$ & 10.04) \\
\hline & $\mathrm{SO}-\mathrm{AD}_{\mathrm{I}}$ & 36546 & 39295 & 58.17 & 0.738 & $(54.03$ & $9.02)$ & 43444 & 46938 & 80.43 & 0.662 & $(74.63$ & 9.37) \\
\hline & MO-AD & 32518 & 35633 & 45.2 & 0.469 & $(33.27$ & 5.96) & 39495 & 42072 & 52.0 & 0.352 & $(33.80$ & $6.28)$ \\
\hline \multirow[t]{3}{*}{ AU6 } & SO-AD & 2.917724 & 6.002718 & 116.00 & 0.777 & (116.00 & $9.10)$ & 3.252887 & 6.565788 & 170.60 & 0.731 & $(170.60$ & $13.54)$ \\
\hline & SO-AD & 2.914147 & 6.034773 & 104.67 & 0.673 & (99.17 & $8.06)$ & 3.245635 & 6.629009 & 154.97 & 0.640 & (146.47 & $12.36)$ \\
\hline & MO-AD & 2.568845 & 6.457802 & 73.6 & 0.387 & $(48.77$ & 5.77) & 2.941543 & 6.263927 & 111.0 & 0.389 & (79.53 & $9.18)$ \\
\hline \multirow{3}{*}{ AU8 } & SO-AD & 9.222880 & 10.51600 & 70.60 & 0.771 & (70.60 & $9.65)$ & 7.804103 & 8.910248 & 78.80 & 0.812 & (78.80 & $11.05)$ \\
\hline & $\mathrm{SO}-\mathrm{AD}_{\mathrm{I}}$ & 9.204716 & 10.72178 & 59.90 & 0.621 & $(56.07$ & 7.97) & 7.796410 & 9.112414 & 66.13 & 0.648 & $(61.93$ & 9.04) \\
\hline & MO-AD & 8.897037 & 10.759520 & 36.2 & 0.303 & $(23.00$ & 4.99) & 7.386325 & 9.000788 & 33.3 & 0.283 & $(22.67$ & 4.81) \\
\hline \multirow[t]{3}{*}{ ANA } & SO-AD & 0.008360 & 0.010359 & 72.40 & 0.752 & $(72.40$ & 2.01) & 0.023771 & 0.026515 & 211.20 & 0.740 & (211.20 & $7.00)$ \\
\hline & $\mathrm{SO}-\mathrm{AD}_{\mathrm{I}}$ & 0.010606 & 0.012647 & 70.30 & 0.698 & $(64.83$ & 2.00) & 0.020551 & 0.023209 & 189.73 & 0.617 & (183.13 & 5.34) \\
\hline & $\mathrm{MO}-\mathrm{AD}_{\mathrm{I}}$ & 0.007488 & 0.009588 & 67.5 & 0.659 & $(59.50$ & 1.98) & 0.007158 & 0.009335 & 133.0 & 0.358 & (91.53 & 4.12) \\
\hline \multirow[t]{3}{*}{ ABA } & SO-AD & 5.101607 & 5.078695 & 68.20 & 0.912 & $(68.20$ & 15.64) & 6.374271 & 6.385199 & 50.20 & 0.854 & $(50.20$ & 9.40) \\
\hline & $\mathrm{SO}-\mathrm{AD}_{\mathrm{I}}$ & 5.077808 & 5.059224 & 56.57 & 0.707 & $(51.90$ & 12.40) & 6.235069 & 6.249418 & 40.30 & 0.614 & (36.87 & $6.59)$ \\
\hline & MO-AD & 4.753375 & 4.789237 & 26.5 & 0.225 & $(13.47$ & 4.79) & 6.198179 & 6.219666 & 24.9 & 0.311 & (15.07 & 4.32) \\
\hline \multirow[t]{3}{*}{$\mathrm{CON}$} & SO-AD & 58.142348 & 62.98518 & 135.40 & 0.692 & (135.40 & 19.63) & 61.601930 & 65.901353 & 124.40 & 0.697 & (124.40 & 19.30) \\
\hline & $\mathrm{SO}-\mathrm{AD}_{\mathrm{I}}$ & 57.845984 & 62.69151 & 118.10 & 0.569 & (110.30 & $16.45)$ & 61.289333 & 65.672337 & 108.17 & 0.568 & $(100.80$ & 15.99) \\
\hline & MO-AD & 50.3219 & $\mathbf{5 7 . 5 9 6 6}$ & 59.9 & 0.219 & $(37.07$ & $8.39)$ & 56.380503 & 62.489223 & 62.6 & 0.257 & $(39.37$ & 9.66) \\
\hline \multirow[t]{3}{*}{ STP } & SO-AD & 3.784825 & 3.810319 & 122.80 & 0.849 & $(122.80$ & $36.25)$ & 4.371739 & 4.459575 & 45.60 & 0.870 & $(45.60$ & 14.49) \\
\hline & SO-AD & 3.556481 & 3.571853 & 98.40 & 0.643 & (91.97 & 27.91) & 4.302168 & 4.399084 & 34.57 & 0.567 & $(30.03$ & 9.32) \\
\hline & $\mathrm{MO}-\mathrm{AD}_{\mathrm{I}}$ & 2.052056 & 2.154450 & 36.7 & 0.139 & $(15.43$ & 7.94) & 4.159594 & 4.255350 & 25.0 & 0.287 & $(11.73$ & 6.19) \\
\hline \multirow[t]{3}{*}{ WAN } & SO-AD & 7.775341 & 8.005151 & 156.00 & 0.845 & (156.00 & $60.23)$ & 14.300552 & 14.573703 & 33.40 & 0.864 & $(33.40$ & 13.09) \\
\hline & SO-AD ${ }_{\mathrm{I}}$ & 7.626420 & 7.883073 & 136.73 & 0.713 & (129.27 & 52.19) & 14.194849 & 14.484166 & 25.43 & 0.622 & $(23.00$ & $10.00)$ \\
\hline & $\mathrm{MO}-\mathrm{AD}_{\mathrm{I}}$ & 5.983361 & 6.674879 & 48.6 & 0.190 & $(27.90$ & $17.52)$ & 13.774738 & 14.009191 & 16.1 & 0.361 & $(12.27$ & 6.19) \\
\hline \multirow[t]{3}{*}{ WIZ } & SO-AD & 3.331755 & 3.574799 & 104.80 & 0.883 & (104.80 & $35.21)$ & 4.034584 & 4.544982 & 52.40 & 0.863 & $(52.40$ & 18.26) \\
\hline & SO-AD & 3.316957 & 3.583501 & 92.80 & 0.750 & $(87.43$ & $30.59)$ & 3.943292 & 4.418400 & 42.47 & 0.659 & $(39.60$ & 14.19) \\
\hline & $\mathrm{MO}-\mathrm{AD}_{\mathrm{I}}$ & 2.629827 & 3.068601 & 43.2 & 0.297 & $(27.57$ & 15.13) & 3.413844 & 3.856717 & 25.0 & 0.351 & $(19.80$ & $8.12)$ \\
\hline \multirow[t]{3}{*}{ MOR } & SO-AD & 0.329428 & 0.328112 & 77.60 & 0.868 & $(77.60$ & 29.29) & 0.361349 & 0.364585 & 31.40 & 0.857 & $(31.40$ & $11.25)$ \\
\hline & SO-AD & 0.263595 & 0.273204 & 58.50 & 0.633 & $(54.50$ & 22.42) & 0.346304 & 0.347567 & 21.20 & 0.557 & (19.43 & 7.80) \\
\hline & $\mathrm{MO}-\mathrm{AD}_{\mathrm{I}}$ & 0.153782 & 0.165901 & 16.5 & 0.144 & ( 9.57 & $6.50)$ & 0.267971 & 0.275199 & 12.8 & 0.305 & ( 9.03 & $5.06)$ \\
\hline \multirow[t]{3}{*}{ TRE } & SO-AD & 0.428898 & 0.432897 & 75.00 & 0.884 & $(75.00$ & 28.12) & 0.595556 & 0.587049 & 33.00 & 0.827 & $(33.00$ & 11.39) \\
\hline & SO-AD & 0.374909 & 0.378188 & 57.00 & 0.653 & $(53.30$ & 21.73) & 0.578306 & 0.573042 & 23.00 & 0.553 & $(20.63$ & $8.36)$ \\
\hline & $\mathrm{MO}-\mathrm{AD}_{\mathrm{I}}$ & 0.202813 & 0.232601 & 20.3 & 0.177 & $(12.23$ & 7.00) & 0.448043 & 0.436540 & 10.4 & 0.229 & $(7.20$ & 4.17) \\
\hline
\end{tabular}


significant differences. This study can be consulted in Appendix B.

Thus, viewing Table 7 and the statistical analysis of Appendix B, we can conclude:

- The multi-objective proposal, for the most accurate point, statistically overcomes the accuracy of the single-objective accuracy oriented approaches. This is an important result, because the use of the mechanism proposed to improve the interpretability of adaptive defuzzification methods together with the MOEA is improving not only their interpretability but also their accuracy.

- As was expected, the interpretability measures of the multi-objective approach for the most accurate point are better than the ones for the singleobjective accuracy oriented approaches.

- Taking into account only the single-objective approaches, $\mathrm{SO}-\mathrm{AD}_{\mathrm{I}(0.1-0.9)}$ outperforms SO-AD. Thus, the mechanism to improve the interpretability also proposed for the single-objective methods, improves their accuracy when using $\mathrm{T}_{\mathrm{L}}=0.1$ and $\mathrm{T}_{\mathrm{H}}=0.9$

Figure 3 shows the representative points for MO$\mathrm{AD}_{\mathrm{I}(0.1-0.9)}, \mathrm{SO}-\mathrm{AD}$ and $\mathrm{SO}-\mathrm{AD}_{\mathrm{I}(0.1-0.9)}$ for TRE dataset obtained using WM rule bases. It shows the approximations of the Pareto fronts achieved by MO$\mathrm{AD}_{\mathrm{I}(0.1-0.9)}$ and the relative position of the results obtained with the single-objective methods, SO-AD and $\mathrm{SO}-\mathrm{AD}_{\mathrm{I}(0.1-0.9) \text {. Similar results are obtained for all }}$ datasets and FS-MOGUL rule bases.

Figure 4 shows a representative example on WIZ dataset in order to reveal that the $\# \mathrm{R}_{\mathrm{F}}$ is moving in the same way as the $\mathrm{R}_{\mathrm{W} \_} \mathrm{AvR}_{\mathrm{TG}}$ index in the approximated
Pareto fronts provided by $\mathrm{MO}-\mathrm{AD}_{\mathrm{I}(0.1-0.9)}$. We plot the solutions from MO-AD $\mathrm{AD}_{\mathrm{I}(0.1-0.9)}$ two-dimensionally, and plot the projections of these solutions on the accuracy$\# \mathrm{R}_{\mathrm{F}}$ and accuracy- $\mathrm{R}_{\mathrm{W}} \mathrm{AvR}_{\mathrm{TG}}$ planes jointly with the single-objective $\mathrm{SO}-\mathrm{AD}$ and $\mathrm{SO}-\mathrm{AD}_{\mathrm{I}(0.1-0.9)}$. In order to retain all the information, in this figure the dominated solutions obtained from the projections have not been removed. Some researchers have also used these kinds of projections for graphic representation when three objectives are optimized together ${ }^{28,57}$.
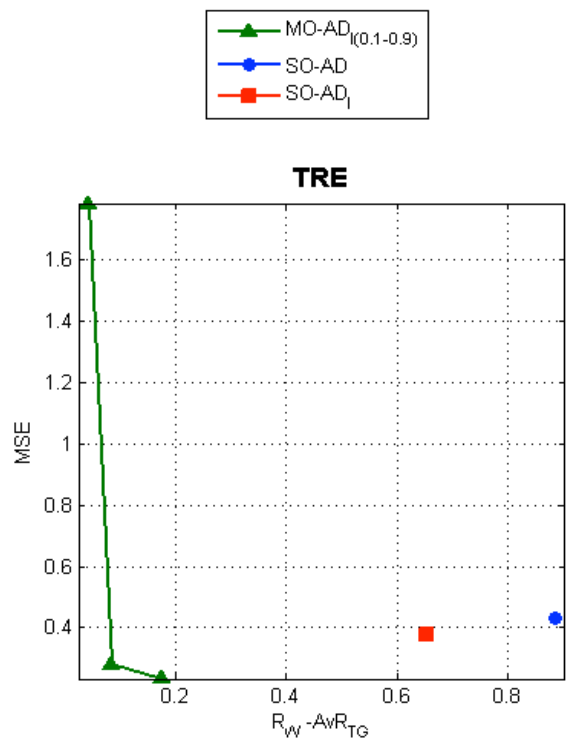

Fig. 3. Average pareto fronts obtained for TRE data sets in the accuracy-interpretability plane using WM rule bases.
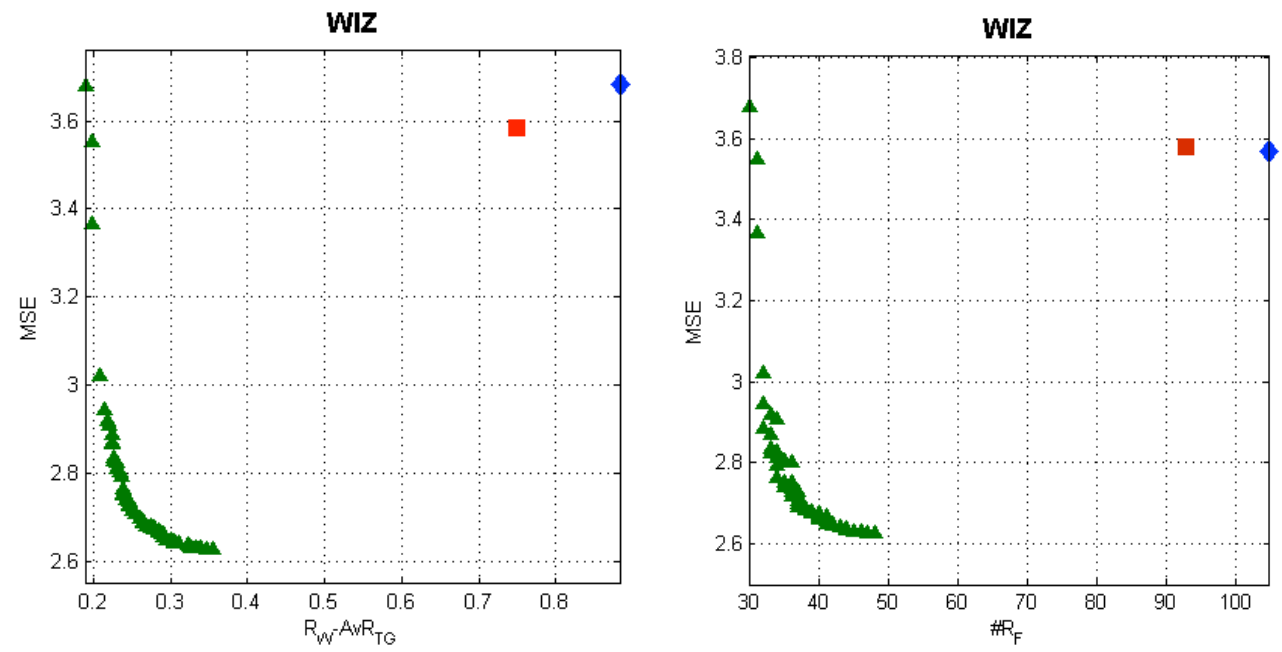

Fig. 4. Example Pareto fronts obtained in WIZ problem. 


\subsection{Second part of the experimental study}

In this subsection we analyse the practical behaviour of the second or adaptive thresholds model proposed.

Table 8 summarizes the FRBSs considered. We compare the adaptive interpretability improvement mechanism approach against two of the previously employed fixed threshold approaches, $\mathrm{T}_{\mathrm{L}}=0.1$ and $\mathrm{T}_{\mathrm{H}}=0.9$, and $\mathrm{T}_{\mathrm{L}}=0.3$ and $\mathrm{T}_{\mathrm{H}}=0.7$. Regarding the MOEA set-up, the initial population was obtained initializing all the individuals randomly (between 0 to 1 in $C_{D}$ part and within the corresponding variation intervals defined in $\mathrm{C}_{\mathrm{T}}$ part) except those whose genes all have value ' 1 ' in the $C_{D}$ part in order to begin the evolutionary process with all the rules activated and without weights, and the $\mathrm{C}_{\mathrm{T}}$ part with $\beta_{\mathrm{T}}=1$, which is $\mathrm{T}_{\mathrm{L}}=0$ and $\mathrm{T}_{\mathrm{H}}=1$.

The rest of the set-up of the MOEA used is the same employed in section 4.1 for the first part of the experimental study.

Table 8. FRBSs considered for comparison

\begin{tabular}{lc}
\hline FRBSs & Description \\
\hline$M O-A D_{I}$ & Multi-Objective FRBSs \\
& $\begin{array}{c}\text { Adaptive Defuzzification with } \\
\text { fixed } \text { mechanism to improve } \\
\text { interpretability }\end{array}$ \\
$M O-A D_{I(A)}$ & $\begin{array}{c}\text { Adaptive Defuzzification with } \\
\text { adaptable mechanism to } \\
\end{array}$ \\
improve interpretability
\end{tabular}

Results and analysis

Tables 9 and 10 show the results for the three representative points: the most accurate, the median, and the most interpretable. Viewing them, we can see that the most accurate solution of the adaptive mechanism $\mathrm{MO}-\mathrm{AD}_{\mathrm{I}(\mathrm{A})}$ is very close to the most accurate fixed thresholds approach $\mathrm{MO}-\mathrm{AD}_{\mathrm{I}(0.1-0.9)}$ and usually, the most interpretable (using the index proposed) obtained by $\mathrm{MO}-\mathrm{AD}_{\mathrm{I}(\mathrm{A})}$ is normally more interpretable than the most interpretable of $\mathrm{MO}-\mathrm{AD}_{\mathrm{I}(0.3-}$ 0.7), but sometimes the most interpretable solution obtained may be unusable because its accuracy is very bad.

However, we actually consider that the aforementioned three representative points do not show the usefulness of this adaptive approach. This time, we needed to use other tools to study the behaviour of the new adaptive interpretability improvement mechanism for adaptive defuzzification systems in order to compare it with the non adaptive approach.

Figure 5 shows an example of the Pareto fronts obtained by the MO-AD $\mathrm{AD}_{\mathrm{I}(\mathrm{A})}$, MO-AD $\mathrm{AD}_{\mathrm{I}(0.1-0.9)}$ and MO$\mathrm{AD}_{\mathrm{I}(0.3-0.7) \text {. It reveals the interest of the solutions }}$ obtained by the MO- $\mathrm{AD}_{\mathrm{I}(\mathrm{A})}$ because the curve is below the two other in most of them, i.e. it has more interpretable solutions taking the same level of accuracy.

For this reason, we used the Two Set Coverage ${ }^{57}$ (CS) ratio previously cited. Their results are shown in Table 11. The best results obtained are highlighted in bold. It can be observed that $\mathrm{MO}-\mathrm{AD}_{\mathrm{I}(\mathrm{A})}$ is better than both, MO-AD $\mathrm{I}_{\mathrm{I}(0.1-0.9)}$ and $\mathrm{MO}-\mathrm{AD}_{\mathrm{I}(0.3-0.7)}$ for almost all problems.

Figure 6 shows an example of the thresholds found by the adaptive width mechanism. Probably the most interesting zones of solutions are those with the lower interpretability index $\left(\mathrm{R}_{\mathrm{W} \_} \mathrm{AvR}_{\mathrm{TG}}\right.$ around 0.04$)$ which keep the error at the lower values (close to 0 ) and thresholds are between $\mathrm{T}_{\mathrm{L}}=0.25$ and $\mathrm{T}_{\mathrm{H}}=0.75$, and $\mathrm{T}_{\mathrm{L}}=0.3$ and $\mathrm{T}_{\mathrm{H}}=0.7$.

Therefore, we can conclude the following:

- The proposal based on the use of adaptive mechanism to improve the interpretability of FRBSs with adaptive defuzzification, MO-AD $\mathrm{D}_{\mathrm{I}(\mathrm{A})}$, allow us to obtain, in a single execution of the algorithm, a set of solutions ranging from the most interpretable to the most accurate without the need to set up thresholds to obtain a more interpretable or more accurate set of solutions.

- The set of solutions obtained with the MO-AD $\mathrm{AD}_{\mathrm{I}(\mathrm{A})}$ approach improves on those obtained with the fixed thresholds mechanism approaches, thus constituting a preferable design option.

\section{Conclusions}

Classically, linguistic fuzzy modelling has focused on the improvement of system accuracy. Recently, there has been a growing interest in interpretability, initially in not significantly affecting the interpretability while improving the accuracy, and now improving the accuracy together with the interpretability.

This evolution has also required an understanding of the different factors and slopes involving the interpretability, which is a subjective concept and thus difficult to evaluate. At present, some works ${ }^{30,31-33}$ propose different taxonomies and key considerations to better achieve and deal with interpretability. 
Table 9. Results obtained by MO-AD for different configurations of thresholds using the WM rule base

\begin{tabular}{|c|c|c|c|c|c|c|c|c|c|c|c|c|c|c|c|c|c|c|c|}
\hline \multirow[b]{2}{*}{ Dataset } & \multicolumn{8}{|c|}{ MAX $_{\text {INT }}$} & \multicolumn{4}{|c|}{ MEDIAN (INT/ACC) } & \multicolumn{7}{|c|}{ MAX $_{\text {ACC }}$} \\
\hline & $\frac{\mathrm{MO}-\mathrm{AD}_{\mathrm{I}}}{\mathrm{T}_{\mathrm{L}}-\mathrm{T}_{\mathrm{H}}}$ & $\mathrm{MSE}_{\text {tra }}$ & $\mathrm{MSE}_{t s t}$ & $\# \mathrm{R}_{\mathrm{F}}$ & $\mathrm{R}_{\mathrm{w}_{-}} \mathrm{AvR}_{\mathrm{TC}}$ & $\mathrm{G}_{\mathrm{G}}\left(\# \mathrm{R}_{\mathrm{W}}\right.$ & $\left.\mathrm{AvR}_{\mathrm{TG}}\right)$ & $\mathrm{MSE}_{t r a}$ & $\mathrm{MSE}_{t s t}$ & $\# \mathrm{R}_{\mathrm{F}}$ & $\mathrm{R}_{\mathrm{W}_{-}} \mathrm{AvR}_{\mathrm{TC}}$ & $\left(\# \mathrm{R}_{\mathrm{W}}\right.$ & $\left.A v R_{T G}\right)$ & $\mathrm{MSE}_{t r a}$ & $\mathrm{MSE}_{t s t}$ & $\# \mathrm{R}_{\mathrm{F}}$ & $\mathrm{R}_{\mathrm{W}_{-}} \mathrm{AvR}_{\mathrm{T}}$ & $\mathrm{rg}_{\mathrm{G}} \# \mathrm{R}_{\mathrm{W}}$ & $A v R_{T G}$ \\
\hline \multirow[t]{3}{*}{ PLA } & $0.1-0.9$ & 6.947800 & 6.940028 & 6.1 & 0.128 & $(0.00$ & $1.02)$ & 2.073691 & 2.091053 & 10.6 & 0.385 & ( 2.23 & $2.48)$ & 1.699226 & 1.759935 & 14.0 & 0.771 & $(10.80$ & $3.25)$ \\
\hline & $0.3-0.7$ & 7.042636 & 7.042633 & 6.0 & 0.125 & ( 0.00 & $1.00)$ & 2.543587 & 2.545364 & 10.4 & 0.309 & ( 0.60 & 2.31) & 1.830941 & 1.900387 & 12.4 & 0.551 & ( 6.13 & 2.75) \\
\hline & Adaptive & 3.516398 & 3.587155 & 5.00 & 0.132 & ( 0.00 & $1.05)$ & 2.157240 & 2.168258 & 9.67 & 0.344 & ( 1.70 & $2.30)$ & 1.690599 & 1.745825 & 14.07 & 0.783 & (11.13 & $3.26)$ \\
\hline \multirow[t]{3}{*}{ QUA } & $0.1-0.9$ & 0.023570 & 0.024276 & 22.7 & 0.179 & ( 4.93 & 2.12) & 0.020914 & 0.022153 & 27.2 & 0.287 & (10.60 & 3.01) & 0.020675 & 0.021944 & 32.6 & 0.448 & (22.67 & 3.79) \\
\hline & $0.3-0.7$ & 0.026361 & 0.027337 & 17.7 & 0.114 & ( 0.13 & $1.80)$ & 0.021700 & 0.022975 & 24.7 & 0.193 & ( 3.13 & $2.62)$ & 0.020897 & 0.022139 & 31.4 & 0.380 & (17.37 & 3.49) \\
\hline & Adaptive & 0.071487 & 0.071611 & 6.10 & 0.018 & ( 0.00 & $0.28)$ & 0.036666 & 0.037420 & 9.97 & 0.063 & ( 0.23 & $0.97)$ & 0.020688 & 0.022138 & 32.97 & 0.450 & (23.70 & $3.66)$ \\
\hline \multirow[t]{3}{*}{ ELE } & $0.1-0.9$ & 57867 & 60608 & 35.8 & 0.167 & ( 7.37 & 3.10) & 35428 & 39094 & 38.6 & 0.285 & (16.30 & 4.48) & 32518 & 35633 & 45.2 & 0.469 & (33.27 & 5.96) \\
\hline & $0.3-0.7$ & 143152 & 150408 & 20.0 & 0.063 & ( 0.03 & 1.77) & 64459 & 70994 & 27.6 & 0.086 & ( 1.17 & 2.16) & 33433 & 35677 & 45.4 & 0.421 & (25.97 & 6.19) \\
\hline & Adaptive & 4515380 & 4510411 & 13.03 & 0.014 & ( 0.00 & 0.39 ) & 308668 & 326805 & 17.60 & 0.049 & ( 0.00 & $1.39)$ & 32809 & 35539 & 45.00 & 0.482 & (32.57 & 6.49) \\
\hline \multirow[t]{3}{*}{ AU6 } & $0.1-0.9$ & 3.487613 & 6.568578 & 84.6 & 0.214 & ( 6.60 & 6.07) & 2.746415 & 6.482094 & 73.4 & 0.293 & (28.57 & (5.57) & 2.568845 & 6.457802 & 73.6 & 0.387 & (48.77 & 5.77) \\
\hline & $0.3-0.7$ & 5.551319 & 9.068401 & 40.9 & 0.086 & ( 0.27 & 2.78) & 3.326684 & 7.252765 & 52.2 & 0.132 & ( 3.43 & $3.84)$ & 2.687347 & 6.430410 & 72.5 & 0.325 & (35.53 & 5.61) \\
\hline & Adaptive & 4.825753 & 8.955610 & 47.60 & 0.109 & ( 1.70 & 3.33) & 3.024116 & 7.687152 & 56.40 & 0.189 & (13.70 & 4.26) & 2.609892 & 6.387879 & 78.97 & 0.441 & (58.43 & $6.20)$ \\
\hline \multirow[t]{3}{*}{ AU8 } & $0.1-0.9$ & 11.281517 & 13.152617 & 32.1 & 0.132 & ( 3.00 & 3.93) & 9.102294 & 11.28545 & 33.9 & 0.201 & $(10.80$ & 4.45) & 8.897037 & 10.759520 & 36.2 & 0.303 & $(23.00$ & 4.99) \\
\hline & $0.3-0.7$ & 21.088986 & 23.062541 & 14.8 & 0.054 & $(0.00$ & $1.93)$ & 10.672853 & 12.84438 & 21.4 & 0.090 & ( 1.13 & 2.91) & 9.127924 & 11.186454 & 35.9 & 0.255 & $(17.23$ & 4.73) \\
\hline & Adaptive & 19.514876 & 20.801083 & 12.77 & 0.045 & $(0.30$ & $1.52)$ & 9.739728 & 11.83919 & 22.57 & 0.120 & ( 5.23 & 2.97) & 8.887143 & 10.698300 & 37.17 & 0.325 & $(25.63$ & 5.13) \\
\hline \multirow[t]{3}{*}{ ANA } & $0.1-0.9$ & 0.647718 & 0.646577 & 63.7 & 0.190 & ( 1.77 & $1.43)$ & 0.107990 & 0.109300 & 67.1 & 0.267 & ( 3.67 & $1.94)$ & 0.007488 & 0.009588 & 67.5 & 0.659 & $(59.50$ & $1.98)$ \\
\hline & $0.3-0.7$ & 0.955815 & 0.960777 & 45.6 & 0.137 & $(0.03$ & $1.09)$ & 0.438822 & 0.440663 & 50.6 & 0.195 & ( 0.70 & $1.52)$ & 0.007551 & 0.009691 & 64.8 & 0.531 & (41.37 & $1.96)$ \\
\hline & Adaptive & 0.360127 & 0.360551 & 38.87 & 0.054 & $(0.00$ & $0.43)$ & 0.104234 & 0.110433 & 49.33 & 0.160 & ( 2.07 & $1.17)$ & 0.007347 & 0.009452 & 66.80 & 0.656 & (59.13 & 1.98) \\
\hline \multirow[t]{3}{*}{$\mathrm{ABA}$} & $0.1-0.9$ & 7.613683 & 7.712487 & 15.2 & 0.083 & ( 2.00 & 2.58) & 4.836747 & 4.858605 & 19.8 & 0.142 & ( 6.23 & 3.66 & 4.753375 & 4.789237 & 26.5 & 0.225 & (13.47 & (4.79) \\
\hline & $0.3-0.7$ & 14.830294 & 14.893969 & 10.3 & 0.044 & $(0.00$ & 1.66) & 6.432483 & 6.432756 & 13.4 & 0.066 & ( 0.37 & 2.42) & 4.821530 & 4.845469 & 23.1 & 0.184 & ( 9.37 & 4.39) \\
\hline & Adaptive & 11.779818 & 11.777811 & 5.30 & 0.027 & $(0.03$ & 1.01) & 5.504223 & 5.571520 & 9.70 & 0.066 & ( 1.20 & 2.19) & 4.761915 & 4.779487 & 25.87 & 0.232 & (13.97 & 4.91) \\
\hline \multirow[t]{3}{*}{$\mathrm{CON}$} & $0.1-0.9$ & 70.753300 & 76.129910 & 83.8 & 0.131 & ( 6.30 & $10.97)$ & 55.1029 & 61.1530 & 71.5 & 0.169 & $(20.23$ & $9.65)$ & 50.3219 & 57.5966 & 59.9 & 0.219 & (37.07 & 8.39) \\
\hline & $0.3-0.7$ & 128.97494 & 134.53928 & 25.9 & 0.030 & $(0.03$ & $3.06)$ & 73.2893 & 83.2969 & 33.2 & 0.049 & ( 1.60 & $4.37)$ & 52.9665 & 59.9898 & 60.0 & 0.198 & (31.23 & 8.43) \\
\hline & Adaptive & 121.13485 & 127.93996 & 28.87 & 0.037 & $(0.53$ & $3.53)$ & 62.424558 & 69.86624 & 38.17 & 0.071 & ( 4.97 & $5.38)$ & 50.580760 & 57.292015 & 64.60 & 0.254 & $(44.00$ & 9.34) \\
\hline \multirow[t]{3}{*}{ STP } & $0.1-0.9$ & 3.708981 & 3.794866 & 25.7 & 0.061 & ( 3.20 & $5.04)$ & 2.129880 & 2.227016 & 29.8 & 0.092 & ( 7.83 & $6.25)$ & 2.052056 & 2.154450 & 36.7 & 0.139 & $(15.43$ & 7.94) \\
\hline & $0.3-0.7$ & 8.334997 & 8.401997 & 10.5 & 0.024 & ( 0.07 & 2.44) & 3.113456 & 3.240279 & 15.9 & 0.039 & ( 1.13 & $3.58)$ & 2.191832 & 2.272137 & 33.8 & 0.106 & ( 9.67 & $6.91)$ \\
\hline & Adaptive & 15.327830 & 15.680952 & 11.33 & 0.019 & ( 0.00 & 1.96) & 2.568037 & 2.731294 & 19.27 & 0.048 & ( 2.27 & $4.00)$ & 2.080961 & 2.147385 & 36.77 & 0.135 & $(14.63$ & 7.88) \\
\hline \multirow[t]{3}{*}{ WAN } & $0.1-0.9$ & 6.463753 & 7.172746 & 38.8 & 0.115 & $(12.30$ & 13.24) & 6.033333 & 6.780082 & 43.1 & 0.146 & $(18.50$ & $15.22)$ & 5.983361 & 6.674879 & 48.6 & 0.190 & (27.90 & $17.52)$ \\
\hline & $0.3-0.7$ & 16.437768 & 17.227865 & 19.2 & 0.029 & $(0.03$ & $5.03)$ & 7.376043 & 8.159211 & 27.6 & 0.052 & ( 0.67 & $8.66)$ & 6.130478 & 6.859088 & 46.0 & 0.140 & $(14.50$ & $16.28)$ \\
\hline & Adaptive & 13.890007 & 13.886866 & 26.77 & 0.052 & ( 0.67 & 8.81) & 6.702816 & 7.416840 & 34.43 & 0.085 & ( 5.10 & 11.93) & 6.033621 & 6.791114 & 46.00 & 0.165 & $(21.27$ & $16.96)$ \\
\hline \multirow[t]{3}{*}{ WIZ } & $0.1-0.9$ & 3.846971 & 4.359892 & 30.5 & 0.147 & ( 7.90 & $10.00)$ & 2.718277 & 3.149809 & 36.1 & 0.211 & $(14.73$ & $12.86)$ & 2.629827 & 3.068601 & 43.2 & 0.297 & (27.57 & 15.13) \\
\hline & $0.3-0.7$ & 24.760387 & 25.488658 & 14.8 & 0.034 & $(0.03$ & 3.11) & 5.940635 & 6.631707 & 19.3 & 0.062 & ( 0.73 & $5.35)$ & 2.734843 & 3.302554 & 45.1 & 0.265 & $(20.30$ & $15.39)$ \\
\hline & Adaptive & 19.506770 & 20.197547 & 17.27 & 0.056 & $(0.23$ & 5.01) & 3.220616 & 3.690454 & 25.80 & 0.115 & ( 3.57 & $8.98)$ & 2.643355 & 3.061785 & 44.60 & 0.311 & (29.27 & $15.63)$ \\
\hline \multirow[t]{3}{*}{ MOR } & $0.1-0.9$ & 1.590566 & 1.564395 & 9.2 & 0.042 & ( 0.77 & 2.97) & 0.201851 & 0.219410 & 12.9 & 0.079 & ( 2.83 & $4.83)$ & 0.153782 & 0.165901 & 16.5 & 0.144 & ( 9.57 & $6.50)$ \\
\hline & $0.3-0.7$ & 3.180415 & 3.323322 & 5.6 & 0.021 & $(0.00$ & 1.64) & 0.551852 & 0.574422 & 8.5 & 0.039 & ( 0.43 & $2.86)$ & 0.163368 & 0.175955 & 18.2 & 0.137 & ( 7.90 & $6.86)$ \\
\hline & Adaptive & 2.080311 & 2.089618 & 5.23 & 0.020 & ( 0.03 & $1.60)$ & 0.339201 & 0.355028 & 8.27 & 0.041 & ( 0.53 & 3.01) & 0.165634 & 0.186429 & 17.07 & 0.148 & ( 9.60 & $6.80)$ \\
\hline \multirow[t]{3}{*}{ TRE } & $0.1-0.9$ & 1.720608 & 1.786207 & 10.3 & 0.045 & ( 0.67 & 2.96) & 0.248659 & 0.280729 & 14.2 & 0.086 & ( 3.10 & $4.75)$ & 0.202813 & 0.232601 & 20.3 & 0.177 & (12.23 & $7.00)$ \\
\hline & $0.3-0.7$ & 4.611414 & 4.668308 & 5.5 & 0.025 & $(0.00$ & 1.80) & 1.005509 & 1.023034 & 7.9 & 0.039 & $(0.23$ & 2.72) & 0.212469 & 0.238197 & 18.9 & 0.144 & ( 7.93 & $6.68)$ \\
\hline & Adaptive & 3.887324 & 3.855478 & 5.20 & 0.019 & $(0.00$ & 1.41) & 0.796229 & 0.820500 & 7.90 & 0.040 & $(0.33$ & $2.74)$ & 0.223408 & 0.229770 & 22.17 & 0.199 & $(13.30$ & $\begin{array}{r}8.09) \\
\end{array}$ \\
\hline
\end{tabular}

Published by Atlantis Press

Copyright: the authors 
Table 10. Results obtained by MO- $\mathrm{AD}_{\mathrm{I}}$ for different configurations of thresholds using the FS_MOGUL rule base

\begin{tabular}{|c|c|c|c|c|c|c|c|c|c|c|c|c|c|c|c|c|c|c|c|}
\hline \multirow[b]{2}{*}{ Dataset } & \multicolumn{8}{|c|}{ MAX $_{\text {INT }}$} & \multicolumn{4}{|c|}{ MEDIAN (INT/ACC) } & \multicolumn{7}{|c|}{$\mathrm{MAX}_{\mathrm{ACC}}$} \\
\hline & $\frac{\mathrm{MO}-\mathrm{AD}_{\mathrm{I}}}{\mathrm{T}_{\mathrm{L}}-\mathrm{T}_{\mathrm{H}}}$ & $\mathrm{MSE}_{\text {tra }}$ & $\mathrm{MSE}_{t s t}$ & $\# \mathrm{R}_{\mathrm{F}}$ & $\mathrm{R}_{\mathrm{W}_{-}} \mathrm{AvR}_{\mathrm{TG}}$ & $G\left(\# R_{W}\right.$ & $\left.\mathrm{AvR}_{\mathrm{TG}}\right)$ & $\mathrm{MSE}_{t r a}$ & $\mathrm{MSE}_{t s t}$ & $\# \mathrm{R}_{\mathrm{F}}$ & $\mathrm{R}_{\mathrm{W}_{-}} \mathrm{AvR}_{\mathrm{TC}}$ & $G\left(\# R_{W}\right.$ & $\left.\mathrm{AvR}_{\mathrm{TG}}\right)$ & $\mathrm{MSE}_{t r a}$ & $\mathrm{MSE}_{t s t}$ & $\# \mathrm{R}_{\mathrm{F}}$ & $\mathrm{R}_{\mathrm{W}_{-}} \mathrm{AvR}_{\mathrm{TC}}$ & $\mathrm{G}\left(\# \mathrm{R}_{\mathrm{W}}\right.$ & $\left.A v R_{T G}\right)$ \\
\hline \multirow[t]{3}{*}{ PLA } & $0.1-0.9$ & 1.574572 & 1.623150 & 21.9 & 0.130 & ( 4.80 & $4.68)$ & 1.171741 & 1.207446 & 29.3 & 0.216 & (11.57 & 6.61) & 1.163733 & 1.201293 & 40.5 & 0.379 & $(28.03$ & 9.16) \\
\hline & $0.3-0.7$ & 5.290166 & 5.346323 & 7.0 & 0.029 & ( 0.00 & 1.38) & 1.754391 & 1.810790 & 13.2 & 0.063 & ( 0.10 & 2.97) & 1.166274 & 1.204826 & 33.5 & 0.251 & $(14.87$ & 7.24) \\
\hline & Adaptive & 3.231820 & 3.335011 & 12.67 & 0.059 & $(0.50$ & $2.65)$ & 1.281801 & 1.301098 & 21.33 & 0.129 & ( 4.40 & 4.73) & 1.163860 & 1.200922 & 41.47 & 0.387 & $(28.50$ & 9.41) \\
\hline \multirow[t]{3}{*}{ QUA } & $0.1-0.9$ & 0.021684 & 0.022334 & 199.7 & 0.292 & $(13.63$ & 26.19) & 0.017291 & 0.018149 & 177.8 & 0.385 & (71.50 & 22.83) & 0.017111 & 0.018167 & 170.8 & 0.553 & (141.50 & 0 24.26) \\
\hline & $0.3-0.7$ & 0.017608 & 0.018610 & 86.4 & 0.129 & (13.13 & $10.08)$ & 0.017135 & 0.018257 & 98.0 & 0.174 & (22.40 & 12.52) & 0.017088 & 0.018183 & 117.2 & 0.268 & $(48.00$ & 16.29) \\
\hline & Adaptive & 0.017483 & 0.018617 & 99.30 & 0.160 & $(16.63$ & 12.46) & 0.017136 & 0.018311 & 105.77 & 0.205 & (28.47 & 14.31) & 0.017086 & 0.018236 & 122.67 & 0.311 & $(62.93$ & 17.35) \\
\hline \multirow[t]{3}{*}{ ELE } & $0.1-0.9$ & 64241 & 67141 & 56.0 & 0.129 & ( 4.23 & $4.10)$ & 42156 & 45526 & 49.5 & 0.228 & (17.10 & 5.09) & 39495 & 42072 & 52.0 & 0.352 & $(33.80$ & $6.28)$ \\
\hline & $0.3-0.7$ & 108723 & 113721 & 23.2 & 0.048 & $(0.07$ & $1.85)$ & 61099 & 65626 & 29.1 & 0.078 & ( 2.07 & $2.56)$ & 40766 & 43063 & 48.5 & 0.258 & $(22.10$ & $5.18)$ \\
\hline & Adaptive & 4026527 & 4027142 & 29.33 & 0.028 & $(0.40$ & 0.99) & 157856 & 155209 & 34.07 & 0.076 & ( 1.97 & 2.51) & 39974 & 42599 & 58.60 & .434 & (43.93 & $7.25)$ \\
\hline \multirow{3}{*}{ AU6 } & $0.1-0.9$ & 3.821884 & 6.764193 & 143.4 & 0.197 & ( 4.50 & $10.80)$ & 3.296278 & 6.516126 & 129.9 & 0.266 & (32.60 & 9.97) & 2.941543 & 6.263927 & 111.0 & 389 & 79.53 & $9.18)$ \\
\hline & $0.3-0.7$ & 4.202431 & 7.836509 & 58.7 & 0.083 & ( 3.43 & $4.31)$ & 3.124690 & 7.149861 & 69.9 & 0.126 & (10.77 & $5.52)$ & 2.976153 & 6.502033 & 88.3 & .226 & $(34.93$ & 7.27) \\
\hline & Adaptive & 4.124317 & 8.088891 & 66.67 & 0.104 & ( 6.47 & 4.94) & 3.086823 & 7.151888 & 77.37 & 0.176 & $(24.03$ & 6.14) & 2.949025 & 6.371336 & 109.33 & 0.379 & (77.10 & $8.94)$ \\
\hline \multirow{3}{*}{ AU8 } & $0.1-0.9$ & 10.610777 & 11.814385 & 24.6 & 0.120 & ( 3.97 & $3.30)$ & 7.526326 & 9.129575 & 27.7 & 0.185 & (11.33 & 3.95) & 7.386325 & 9.000788 & 33.3 & 283 & $(22.67$ & 4.81) \\
\hline & $0.3-0.7$ & 19.910480 & 20.495670 & 14.7 & 0.056 & ( 0.00 & $2.00)$ & 9.872984 & 11.83105 & 19.3 & 0.081 & ( 0.37 & $2.76)$ & 7.505406 & 9.082736 & 32.1 & 0.238 & $(17.17$ & $4.52)$ \\
\hline & Adaptive & 18.357268 & 19.391021 & 10.00 & 0.036 & $(0.27)$ & $1.20)$ & 8.196575 & 9.935652 & 19.33 & 0.106 & ( 4.20 & $2.76)$ & 7.398018 & 8.961176 & 34.93 & 0.305 & $(24.73$ & $5.10)$ \\
\hline \multirow[t]{3}{*}{ ANA } & $0.1-0.9$ & 0.044437 & 0.047909 & 174.4 & 0.188 & $(12.07$ & 4.67) & 0.013463 & 0.015529 & 154.4 & 0.250 & (44.00 & 4.24) & 0.007158 & 0.009335 & 133.0 & .358 & $(91.53$ & $4.12)$ \\
\hline & $0.3-0.7$ & 0.126768 & 0.126480 & 85.7 & 0.094 & ( 8.33 & 2.16) & 0.015763 & 0.018568 & 92.5 & 0.125 & (10.17 & 2.93) & 0.007180 & 0.009461 & 108.3 & 216 & $(34.20$ & $3.92)$ \\
\hline & Adaptive & 0.143600 & 0.143536 & 115.67 & 778 & ( 3.40 & 2.05) & 0.033059 & 0.036042 & 122.23 & 0.119 & (11.07 & 2.72) & 0.007096 & 0.009207 & 125.23 & 321 & (77.90 & 3.97) \\
\hline \multirow[t]{3}{*}{ ABA } & $0.1-0.9$ & 10.034018 & 9.980401 & 15.6 & 0.098 & ( 1.10 & 2.33) & 6.252071 & 6.261997 & 20.2 & 0.180 & ( 5.57 & $3.34)$ & 6.198179 & 6.219666 & 24.9 & 0.311 & $(15.07$ & $4.32)$ \\
\hline & $0.3-0.7$ & 13.471095 & 13.490648 & 9.1 & 0.058 & $(0.00$ & $1.56)$ & 6.933849 & 6.956984 & 13.8 & 0.099 & ( 0.70 & 2.45) & 6.204145 & 6.222632 & 22.9 & 0.220 & $(7.90$ & 3.77) \\
\hline & Adaptive & 11.046818 & 11.051219 & 5.73 & 0.036 & $(0.07$ & $0.94)$ & 6.615973 & 6.628668 & 10.77 & 0.088 & ( 1.67 & 1.92) & 6.197562 & 6.219388 & 22.13 & 0.276 & $(13.50$ & $3.80)$ \\
\hline \multirow[t]{3}{*}{$\mathrm{CON}$} & $0.1-0.9$ & 67.672232 & 71.789422 & 86.8 & 0.143 & ( 5.13 & 12.02) & 59.010937 & 65.03955 & 66.0 & 0.201 & $(25.23$ & 9.74) & 56.380503 & 62.489223 & 62.6 & 257 & (39.37 & $9.66)$ \\
\hline & $0.3-0.7$ & 116.57328 & 123.10188 & 27.7 & 0.036 & $(0.30$ & $3.45)$ & 66.961798 & 73.82797 & 36.8 & 0.066 & ( 2.67 & $5.44)$ & 57.450287 & 63.305839 & 58.3 & 189 & $(24.53$ & 8.79) \\
\hline & Adaptive & 102.84723 & 110.31467 & 26.50 & 338 & ( 0.47 & $3.56)$ & 61.63860 & 67.58694 & 37.37 & 0.078 & ( 4.90 & 5.72) & 56.389478 & 62.40864 & 58.00 & .227 & $(33.40$ & $9.06)$ \\
\hline \multirow[t]{3}{*}{ STP } & $0.1-0.9$ & 5.405339 & 5.474713 & 13.3 & 0.096 & $(1.33$ & $3.21)$ & 4.259753 & 4.362481 & 18.6 & 0.167 & ( 4.63 & 4.54) & 4.159594 & 4.255350 & 25.0 & 0.287 & (11.73 & 6.19) \\
\hline & $0.3-0.7$ & 8.748136 & 8.816542 & 7.9 & 0.058 & ( 0.00 & $2.25)$ & 4.455629 & 4.560821 & 14.7 & 0.125 & ( 2.67 & 3.75) & 4.194782 & 4.309624 & 24.9 & 0.252 & $(8.50$ & $6.22)$ \\
\hline & Adaptive & 12.726416 & 12.816972 & 5.17 & 0.028 & $(0.00$ & 1.07) & 4.374793 & 4.494771 & 13.10 & 0.110 & ( 2.67 & 3.18) & 4.165515 & 4.247484 & 24.87 & .284 & $(11.53$ & 6.17) \\
\hline \multirow[t]{3}{*}{ WAN } & $0.1-0.9$ & 26.310868 & 26.725976 & 9.6 & 88 & $(0.53$ & $2.86)$ & 522565 & 14.77936 & 13.3 & 0.193 & ( 4.40 & $4.46)$ & 13. & 14.009191 & 16.1 & 361 & $(12.27$ & $6.19)$ \\
\hline & $0.3-0.7$ & 32.988571 & 34.115293 & 7.9 & 0.065 & ( 0.00 & $2.26)$ & 15.540758 & 16.02159 & 11.5 & 0.122 & ( 0.93 & $3.81)$ & 13.948231 & 14.207306 & 15.2 & 0.302 & ( 9.47 & $5.61)$ \\
\hline & Adaptive & 63.395682 & 62.167748 & 5.17 & 0.036 & $(0.03$ & 1.20) & 14.83103 & 15.04641 & 9.77 & 0.141 & ( 2.57 & $3.46)$ & 13.770163 & 13.98595 & 15.83 & 363 & $(12.60$ & $6.25)$ \\
\hline \multirow[t]{3}{*}{ WIZ } & $0.1-0.9$ & 12.545764 & 13.543774 & 15.7 & 0.107 & ( 2.57 & 4.18) & 3.881428 & 4.467590 & 19.7 & 0.193 & ( 7.50 & 6.11) & 3.413844 & 3.856717 & 25.0 & 0.351 & $(19.80$ & $8.12)$ \\
\hline & $0.3-0.7$ & 34.337238 & 36.299840 & 10.5 & 0.054 & $(0.00$ & 2.74) & 6.706427 & 7.391861 & 14.5 & 0.091 & ( 0.87 & 4.18) & 3.547122 & 4.014734 & 24.5 & 0.291 & $(14.73$ & 7.61) \\
\hline & Adaptive & 68.862557 & 68.324376 & 7.23 & 29 & ( 0.03 & $1.50)$ & 29783 & 11.72132 & 11.77 & 0.093 & ( 1.80 & $3.86)$ & 3.419498 & 3.854768 & 24.50 & 358 & $(20.27$ & $8.28)$ \\
\hline \multirow[t]{3}{*}{ MOR } & $0.1-0.9$ & 3.056375 & 3.052106 & 6.0 & & $(0.03$ & 1.89) & & 39410 & 8.6 & 0.134 & ( 2.57 & 2.93) & .267971 & 0.275199 & 12.8 & 305 & ( 9.03 & $5.06)$ \\
\hline & $0.3-0.7$ & 3.689980 & 3.747015 & 5.8 & 0.050 & $(0.00$ & $1.58)$ & 0.548342 & 0.553402 & 7.8 & 0.109 & ( 1.50 & 2.69) & 0.283597 & 0.290467 & 13.0 & 0.293 & $(8.13$ & $5.15)$ \\
\hline & Adaptive & 2.081246 & 2.046311 & 5.07 & 0.044 & $(0.00$ & 1.38) & 0.364971 & 0.368820 & 7.30 & 0.137 & ( 3.07 & 2.77) & 0.293933 & 0.306642 & 12.93 & 0.321 & ( 9.23 & 5.47) \\
\hline \multirow[t]{3}{*}{ TRE } & $0.1-0.9$ & 4.887197 & 5.066371 & 5.8 & 0.054 & $(0.17$ & $1.80)$ & 0.806103 & 0.792245 & 8.7 & 0.104 & ( 0.87 & $3.17)$ & 0.448043 & 0.436540 & 10.4 & 0.229 & $(7.20$ & 4.17) \\
\hline & $0.3-0.7$ & 4.886871 & 4.991007 & 5.7 & 0.046 & $(0.00$ & 1.62) & 0.991394 & 0.975439 & 8.0 & 0.084 & ( 0.23 & 2.81) & 0.455389 & 0.437021 & 10.3 & 0.211 & ( 6.17 & $4.10)$ \\
\hline & Adaptive & 3.762724 & 3.686490 & 5.00 & 0.043 & $(0.00$ & 1.49) & 0.906458 & 0.912706 & 6.73 & 0.080 & ( 0.17 & 2.68) & 0.449993 & 0.436562 & 10.90 & 0.246 & $(7.93$ & 4.38) \\
\hline
\end{tabular}

Published by Atlantis Press

Copyright: the authors 

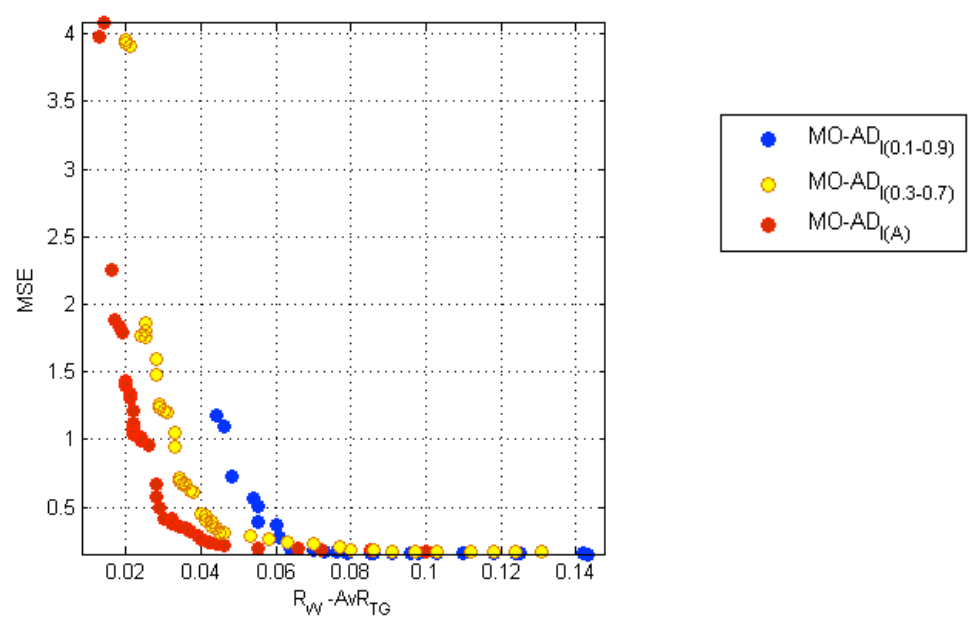

Fig. 5. Example Pareto fronts and Thresholds obtained in MOR problem

Table $11 \mathrm{CS}$ ratios obtained in the accuracy-interpretability plane

\begin{tabular}{|c|c|c|c|c|c|c|c|c|}
\hline \multirow[b]{2}{*}{ Datasets } & \multirow[b]{2}{*}{ Adaptive } & \multirow[b]{2}{*}{$0.1 \_0.9$} & \multicolumn{3}{|c|}{$W M$} & \multicolumn{3}{|c|}{$F S M O G U L$} \\
\hline & & & Adaptive & $0.3 \_0.7$ & Adaptive & $0.1 \_0.9$ & Adaptive & $0.3 \_0.7$ \\
\hline & $v s$ & $v s$. & $v s$ & $v s$. & $v s$. & $v s$ & vs. & vs. \\
\hline & 0.10 .9 & Adaptive & 0.30 .7 & Adaptive & 0.10 .9 & Adaptive & $\begin{array}{ll}0.3 & 0.7\end{array}$ & Adaptive \\
\hline PLA & 0.733 & 0.205 & $\begin{array}{l}0.788 \\
\end{array}$ & 0.119 & 0.825 & 0.373 & 0.363 & 0.708 \\
\hline QUA & 0.278 & 0.671 & 0.416 & 0.491 & 0.815 & 0.200 & 0.381 & 0.875 \\
\hline ELE & 0.263 & 0.554 & 0.243 & 0.641 & 0.563 & 0.321 & 0.144 & 0.815 \\
\hline AU6 & 0.675 & 0.445 & 0.811 & 0.211 & 0.605 & 0.502 & 0.299 & 0.815 \\
\hline AU8 & 0.683 & 0.363 & 0.709 & 0.447 & 0.806 & 0.337 & 0.803 & 0.399 \\
\hline ANA & 0.830 & 0.051 & 0.966 & 0.001 & 0.904 & 0.008 & 0.613 & 0.227 \\
\hline ABA & 0.726 & 0.157 & 0.906 & 0.079 & 0.822 & 0.140 & 0.922 & 0.112 \\
\hline $\mathrm{CON}$ & 0.643 & 0.182 & 0.554 & 0.424 & 0.912 & 0.063 & 0.678 & 0.397 \\
\hline STP & 0.470 & 0.329 & 0.595 & 0.420 & 0.675 & 0.307 & 0.845 & 0.180 \\
\hline WAN & 0.654 & 0.267 & 0.531 & 0.478 & 0.910 & 0.149 & $\mathbf{0 . 9 3 7}$ & 0.099 \\
\hline WIZ & 0.613 & 0.297 & 0.591 & 0.253 & 0.807 & 0.198 & 0.886 & 0.105 \\
\hline MOR & 0.627 & 0.187 & 0.794 & 0.164 & 0.792 & 0.154 & 0.860 & 0.125 \\
\hline TRE & 0.439 & 0.292 & $\mathbf{0 . 6 7 7}$ & 0.297 & 0.772 & 0.105 & 0.802 & 0.127 \\
\hline
\end{tabular}

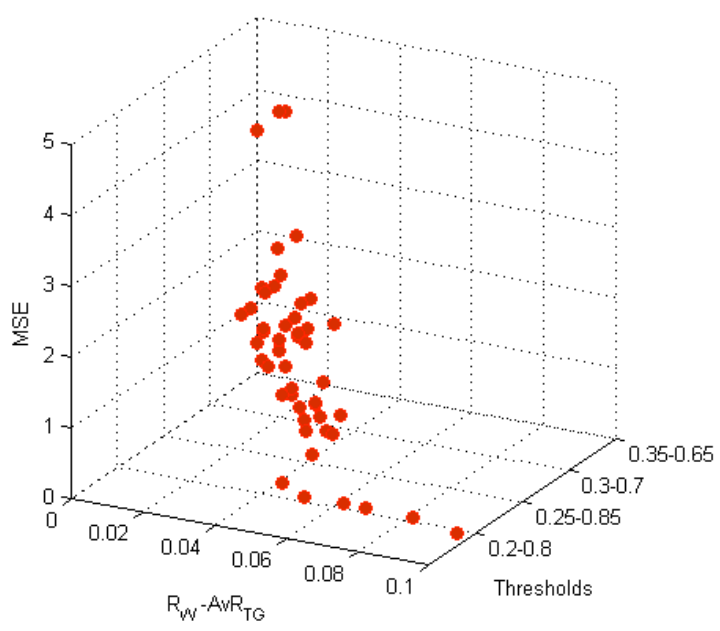

Fig. 6. Example of thresholds found by the adaptive width mechanism in MOR problem.
The most spread adaptive defuzzification, based on the use of rule weights, improves significantly the accuracy of the FRBSs, but reduces the system interpretability noticeably. In this work, and making use of an important instrument nowadays in the development of accurate and interpretable FRBSs such as multi-objective evolutionary algorithms, we propose a way to improve the interpretability of this kind of adaptive defuzzification systems also improving their accuracy. This is carried out by introducing a mechanism to reduce the number of rules, the number of rules with weights and proposing an interpretability index that also involves the measure of rules triggered 
jointly, to reach different slopes of the interpretability together. The methodology proposed can be selfadaptive, and produces a set of solutions with different balance, from the most interpretable to the most accurate, also improving the accuracy of this kind of classical adaptive defuzzification accuracy oriented methods, as shown by developing an experimental study with thirteen data sets, two different rule bases, statistical tests and a measure to compare multiobjective Pareto fronts.

It is important to note that adaptive defuzzification, and thus the proposal developed in this paper, can be combined with other methodologies to design or improve the accuracy or interpretability of fuzzy rule based systems. It may be viewed as an additional element to use within this context.

We consider that together with interpretability comprehension and advances, methods to improve interpretability could be enhanced in the near future, based on the fine balanced combination of measures and slopes of interpretability.

\section{Acknowledgments}

Paper supported in part by the Spanish Ministry of Economy and Competitiveness under grant no. TIN2008-06681-C06-06 and FEDER Funds.

\section{References}

1. L. A. Zadeh Fuzzy sets, Information and Control 8 (1965) 338-353.

2. L. A Zadeh, The concept of a linguistic variable and its application to approximate reasoning, Part I, Inf. Sci. 8 (1975) 199-249. Parts II and III, 8, 9, 301-357, 43-80.

3. E. H. Mamdani, Application of fuzzy logic to approximate reasoning using linguistic systems, IEEE Trans. on Computers 26(12) (1977) 1182-1191.

4. H. Hellendoorn and D. Driankov, Fuzzy Model Identification, (Springer-Verlag, London, UK, 1997).

5. R Alcalá., J. Alcalá-Fdez, M. J. Gacto and F. Herrera, Hybrid learning methods to get the interpretabilityaccuracy trade-off in fuzzy modeling, SoftComp. 10(9) (2006) 717-734.

6. J. Casillas, O. Cordón, F. Herrera, L. Magdalena (eds) Accuracy improvements in linguistic fuzzy modeling, Studies in Fuziness and Soft Computing, (Springer, Heidelberg 2003), pp. 129.

7. J. Casillas, O. Cordón, F. Herrera, L. Magdalena (eds) Interpretability issues in fuzzy modeling, Studies in Fuzziness and Soft Computing, (Springer, Heidelberg 2003) pp. 128.

8. H. Ishibuchi, K. Nozaki, N. Yamamoto and H. Tanaka, Selecting fuzzy if-then rules for classification problems using genetic algorithms, IEEE Trans. on Fuzzy Sys. 3(3) (1995) 260-270.

9. H. Ishibuchi, T. Murata and I. B. Turksen, Selecting linguistic classification rules by two-objective genetic algorithms, in Proc. of the IEEE Int. Conf. on Sys. Man, Cybern. (Vancouver, Canada, 1995), pp. 1410-1415.

10. H. Ishibuchi and T. Murata, Multi-objective genetic local search algorithm, in Proc. Third IEEE Int. Conf. on Evolut. Comput.. (Japan, 1996), pp. 119-124.

11. H. Ishibuchi, T. Murata and I. B. Turksen, Singleobjective and two-objectie genetic algorithms for selecting linguistic rules for pattern classification problems, Fuzzy Sets and Sys. 89(2) (1997) 135-150.

12. Y. Jin, Fuzzy modeling of high-dimensional systems: Complexity reduction and interpretability improvement, IEEE Trans. on Fuzzy Sys. 8(2) (2000) 212-221.

13. H. Ishibuchi and T. Murata, Minimizing the fuzzy rule base and maximizing its performance by a multiobjective genetic algorithms, in Proc. 6th IEEE Int. Conf. Fuzzy Sys. (1997) pp. 259-264.

14. J. Alcalá-Fdez, F. Herrera, F. Márquez and A. Peregrín Increasing fuzzy rules cooperation based on evolutionary adaptive inference systems, Int. J. Intell. Sys. 22(9) (2007) 1035-1064.

15. O. Cordón , F. Herrera , F. A. Márquez and A. Peregrín, A study on the evolutionary adaptive defuzzification methods in fuzzy modeling, Int. J. of Hybrid Intell. Sys. 1(1) (2004) 36-48.

16. F. A. Márquez, A. Peregrín and F. Herrera, Cooperative evolutionary learning of linguistic fuzzy rules and parametric aggregation connectors for Mamdani fuzzy systems, IEEE Trans. on Fuzzy Sys. 15(6) (2007) 11681178.

17. H. Ishibuchi and T. Murata, Learning of fuzzy classification rules by a genetic algorithm, Electronics and Communications in Japan (Part III: Fundamental Electronic Science), 80(3) (1997),37-46.

18. K. Nozaki, H. Ishibuchi and H.Tanaka, Adaptive Fuzzy Rule-Based Classification Systems, IEEE Trans. on Fuzzy Sys. 4(3) (1996) 238-250.

19. H. Ishibuchi, K. Nozaki and H. Tanaka, Efficient Fuzzy Partition of Pattern Space for Classification Problems, Fuzzy Sets and Sys. 59(3) (1993) 295-304.

20. R. Alcalá, J. Casillas, O. Cordón and F. Herrera, Linguistic Modeling with Weighted Double-Consequent Fuzzy Rules Based on Cooperative Coevolutionary Learning, Integrated Computer Aided Engineering 10(4) (2003) 343-355.

21. J. Casillas, F. Herrera, R. Pérez, M. J. del Jesus and P. Villar $\mathrm{P}$, Special issue on genetic fuzzy systems and the interpretability accuracy trade-off, Int. J. of Approximate Reasoning 44 (2007) 1-90.

22. J. González, I. Rojas, H. Pomares, L. J. Herrera, A. Guillén, J. M. Palomares and F. Rojas , Improving the accuracy while preserving the interpretability of fuzzy function approximators by means of multi-objective 
evolutionary algorithms, Int. J. of Approximate Reasoning 44 (2007) 32-44.

23. M. J. Gacto, R. Alcalá, and F. Herrera, Adaptation and Application of Multi-Objective Evolutionary Algorithms for Rule Reduction and Parameter Tuning of Fuzzy RuleBased Systems, Soft Comput. 13(5) (2009) 419-436.

24. H. Ishibuchi, and Y. Nojima, Analysis of interpretabilityaccuracy tradeoff of fuzzy systems by multiobjective fuzzy genetics-based machine learning, Int. J. of Approximate Reasoning 44 (2007) 4-31.

25. M. Antonelli, D. Pietro, B. Lazzerini and F. Marcelloni, Multi-objective evolutionary learning of granularity, membership function parameters and rules of Mamdani fuzzy systems, Evolutionary Intell., Special Issue on GFS: New Advances, 2 (2009) 21-37, doi: 10.1007/s12065-009-0022-3.

26. R. Alcalá, M. J. Gacto, F. Herrera and J. Alcalá-Fdez, A multi-objective genetic algorithm for tuning and rule selection to obtain accurate and compact linguistic fuzzy rule-based systems, Inter. J. of Uncertainty, Fuzziness and Knowledge-Based Sys. 15(5) (2007) 539-557.

27. A. Botta, B. Lazzerini, F. Marcelloni and D. Stefanescu, Context adaptation of fuzzy systems through a multiobjective evolutionary approach based on a novel interpretability index, SoftComput. 13(5) (2009) 437449.

28. M. J. Gacto, R. Alcalá and F. Herrera, Integration of an index to preserve the semantic interpretability in the multio-objective evolutionary rule selection and tuning of linguistic fuzy systems, IEEE Trans. on Fuzzy Sys. 18(3) (2010) 515-531.

29. M. Cococcioni, P. Ducange, B. Lazzerini and F. Marcelloni, A Pareto based multi-objective evolutionary approach to the identification of Mamdani fuzzy systems, Soft Comput. 11 (2007) 1013-1031.

30. C. Mencar and A. Fanelli, Interpretability constraints for fuzzy information granulation, Inf. Sci. 178(24) (2008) 4585-4618.

31. M. Zhou and J. Q. Gan, Low-level interpretability and high-level interpretability: a unified view of data-driven interpretable fuzzy system modeling, Fuzzy Sets and Sys. 159(23) (2008) 3091-3131.

32. J. M. Alonso, L. Magdalena and G. Gonzalez-Rodríguez, Looking for a good fuzzy system interpretability index:An experimental approach,. Int. J. of Approximate Reasoning 51 (2009) 115-134.

33. M. J. Gacto, R. Alcalá, and F. Herrera, Interpretability of Linguistic Fuzzy Rule-Based Systems: An Overview of Interpretability Measures. Inf. Sci. (2011) doi: 10.1016/j.ins.2011.02.021.

34. D. Nauck, Measuring interpretability in rule-based classification systems, in Proc. of the 12th IEEE Int. Conf. on Fuzzy Sys., 1(2) (2003), pp. 196-201.

35. R. Alcalá, J. Alcalá-Fdez., F. Herrera and J. Otero, Genetic learning of accurate and compact fuzzy rule based systems based on the 2-tuples linguistic representation, Int.. J. of Approximate Reasoning 44 (2007) 45-64.

36. S. Guillaume and B. Charnomordic, A new method for inducing a set of interpretable fuzzy partitions and fuzzy inference systems from data, in J. Casillas, O. Cordón, F. Herrera, L. Magdalena (Eds.) Interpretability issues in fuzzy modeling. Springer-Verlag, 2003, pp. 148-175.

37. S. Guillaume and B. Charnomordic, Generationg an interpretable family of fuzzy partitions from data, IEEE Trans. on Fuzzy Sys. 12(3) (2004) 324-335.

38. C. A. Coello, D. A. Van Veldhuizen and G. B. Lamont, Evolutionary algorithms for solving multi-objective problems (Kluwer Academic Publishers, 2002).

39. K. Deb. Multi-objective optimization using evolutionary algorithms (John Wiley \& Sons, NY, USA, 2001).

40. A. A. Márquez, F. A. Márquez and A. Peregrín, Rule base and adaptive fuzzy operators cooperative learning of Mamdani fuzzy systems with multi-objective genetic algorithms, Evolut. Intell. 2 (2009) 39-51.

41. H. Ishibuchi, T. Nakashima, and T. Murata, Threeobjective genetics based machine learning for linguistic rule extraction, Inf. Sci. 136 (2001) 109-133.

42. H. Ishibuchi and T. Yamamoto, Fuzzy rule selection by multi-objective genetic local search algorithms and rule evaluation measures in data mining, Fuzzy Sets and Sys. 141(1) (2004) 59-88.

43. O. Cordón, M. del Jesus, F. Herrera, L. Magdalena and P. Villar, A multiobjective genetic learning process for joint feature selection and granularity and context learning in fuzzy rule-based classification systems, in: J. Casillas, O. Cordón, F. Herrera, L. Magdalena (Eds.) Interpretability issues in fuzzy modeling. Springer-Verlag, 2003) pp. 7999.

44. H. Ishibuchi and T. Yamamoto, Interpretability issues in fuzzy genetics-based machine learning for linguistic modelling, in: J. Jawry, J. G. Shanahan, A. L. Ralescu (Eds.) Modelling with words: Learning, fusion, and reasoning within a formal linguistic representation framework, Vol. 2873 of Lecture Notes in Computer Science, Springer-Verlag, Berlin, Heidelberg, 2003, pp. 209-228.

45. J. S. Cho and D. J. Park, Novel fuzzy logic control based on weighting of partially inconsistent rules using neural network, J. of Intell. and Fuzzy Sys., 8 (2000) 99-110.

46. D. Nauck and R. Kruse, How the learning of rule weights affects the interpretability of fuzzy systems, in Proc. Seventh IEEE Int. Conf. Fuzzy Sys. (1998) 1235-1240.

47. H. Ishibuchi and T. Yamamoto, Rule weight specification in fuzzy rule-based classification systems, IEEE Trans. on Fuzzy Sys. 13(4) (2005) 428-435.

48. H. Ishibuchi and T. Yamamoto, Trade-off between the number of fuzzy rules and their classification performance, in: J. Casillas, O. Cordón, F. Herrera, L. Magdalena (Eds.) Accuracy improvements in linguistic fuzzy modeling. Springer-Verlag, 2003, pp. 72-99.

49. F. Cheong and R. Lai, Constraining the optimization of a fuzzy logic controller using an enhanced genetic 
algorithm, IEEE Trans. Sys., Man, Cybern. - Part B: Cybernetics 30(1) (2000) 31-46.

50. K. Deb, S. Agrawal, A. Pratab and T. Meyarivan, A fast and elitist multiobjective genetic algorithm: NSGA-II, IEEE Trans. Evolut. Comput. 6(2) (2002) 182-197.

51. A.A. Márquez, F.A. Márquez and A. Peregrín, A Multiobjective Evolutionary Algorithm with an Interpretability Improvement Mechanism for Linguistic Fuzzy Systems with Adaptive Defuzzification. 2010 IEEE World Congress on Computational Intelligence (WCCI 2010 FUZZ-IEEE 2010). Barcelona (Spain, 2010) 277-283.

52. O. Cordón and F. Herrera, A three-stage evolutionary process for learning descriptive and approximate fuzzy logic controller knowledge bases from examples, Int. $J$. of Approximate Reasoning 17(4) (1997) 369-407.

53. D. Driankov., H. Haellendoorn and M. Reinfrank , An Introduction to Fuzzy Control_(Springer_Verlag 1993).

54. C. C. Lee, Fuzzy logic in control Systems fuzzy logic controller parts I and II, IEEE Trans. Sys., Man, Cybern. 20 (1990) 404-435.

55. J. Alcalá-Fdez, L. Sánchez, S. García, M. del Jesus, S. Ventura, J. Garrell, J. Otero, C. Romero, J. Bacardit, V. Rivas, J. Fernández and F. Herrera, KEEL: A software tool to assess evolutionary algorithms to data mining problems, Soft Comput. 13(3) (2009) 307-318.

56. L. X. Wang and J.M. Mendel, Generating fuzzy rules by learning from examples, IEEE Trans. Sys., Man., Cybern., 22(6) (1992) 1414-1427.

57. R. Alcalá, P. Ducange, F. Herrera, B. Lazzerini and F. Marcelloni, A Multi-Objective Evolutionary Approach to Concurrently Learn Rule and Data Bases of Linguistic Fuzzy Rule-Based Systems. IEEE Trans. on Fuzzy Sys. 17(5) (2009) 1106-1122.

58. E. Zitzler, K. Deb and L. Thiele, Comparison of Multiobjective Evolutionary Algorithms: Empirical Results, Evolut. Comput. 8(2) (2000) 173-195

59. J. Demšar, Statistical comparisons of classifiers over multiple data sets, J. Mach Learn. Res. 7 (2006) 1-30.

60. S. García and F. Herrera, An extension on statistical comparisons of classifiers over multiple data sets for all pairwise comparisons. J. Mach Learn. Res. 9 (2008) 2579-2596.

61. S. García, A. Fernández, J. Luengo and F. Herrera, A study of statistical techniques and performance measures for genetics-based machine learning: Accuracy and interpretability, Soft Comput. 13(10) (2009) 959-977.

62. S. García, A. Fernández , J. Luengo and F. Herrera, Advanced nonparametric tests for multiple comparisons in the design of experiments in computational intelligence and data mining: Experimental Analysis of Power, Inf. Sci. 180(10) (2010) 2044-2064. doi:10.1016/j.ins.2009.12.010.

63. D. J. Sheskin, Handbook of Parametric and Nonparametric Statistical Procedures, (CRC Press, Boca Raton, FL, 2003).

64. F. Wilcoxon Individual comparisons by ranking methods, Biometrics 1 (1945) 80-83.
65. M. Friedman, The use of ranks to avoid the assumption of normality implicit in the analysis of variance, $J$. of the American Statistical Association 32 (1937) 674-701.

66. H. Finner, On a monotonicity problem in step-down multiple test procedures, $J$. of the American Statistical Association 88 (1993) 920-923. 


\section{Appendix A.}

\section{Statistical analysis of the comparison between the different thresholds}

Tables A.1 to A.6 show the rankings of the different methods considered in this study for WM and FS_MOGUL rule bases, respectively. This study also took into account the $\# \mathrm{R}_{\mathrm{F}}$ measure in order to confirm the relation between $\mathrm{R}_{\mathrm{W}} \mathrm{AvR}_{\mathrm{TG}}$ index and $\# \mathrm{R}_{\mathrm{F}}$ measure. The Friedman test tells us that there are significant differences among the results observed in all data-sets when the $\mathrm{p}$-fried $<0.05$. Indeed, for MAX ACC, MEDIAN INT/ACC and the MAX INT there are significant differences between the uses of different thresholds. However, in all points the best ranking is obtained by MO-AD $\mathrm{I}_{\mathrm{I}(0.1-0.9)}$ for the accuracy and the MO-AD $\mathrm{I}_{\mathrm{I}(0.3-0.7)}$ for the index of $\mathrm{R}_{\mathrm{W} \_} \mathrm{AvR}_{\mathrm{TG}}$ and $\# \mathrm{R}_{\mathrm{F}}$ measure.

In almost all cases (excepting MAX $\mathrm{ACC}$ for $\# \mathrm{R}_{\mathrm{F}}$ ) we now can apply Finner post-hoc procedure to compare the best ranking method in each case with the remaining methods. Tables A.7 to A.12 present these results. In these tables, the algorithms are ordered with respect to the p-value obtained with respect to control algorithm. Finner's test rejects the hypothesis of equality when the p-Finner is $<0.05$. Indeed, the Finner's test rejects the hypothesis of equality for MSE $_{\text {TST }}$ for MAX ACC, MAX INT and MEDIAN INT/ACC point when the control algorithm is

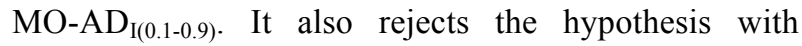
MO-AD $\mathrm{D}_{\mathrm{I}(0.3-0.7)}$ methods in $\mathrm{R}_{\mathrm{W}_{-}} \mathrm{AvR}_{\mathrm{TG}}$ for all representative points.

On the other hand, it also rejects the hypothesis with MO-AD $\mathrm{I}_{(0.3-0.7)}$ methods in $\# \mathrm{R}_{\mathrm{F}}$ in MAX INT and MEDIAN INT/ACC point but not in MAX ACC. Nevertheless, in all cases the best algorithm (control algorithm) is $\mathrm{MO}-\mathrm{AD}_{\mathrm{I}(0.3-0.7) \text {. }}$.

Table A.1 Rankings obtained through Friedman's test for different values of thresholds on $\mathrm{MSE}_{\mathrm{TST}}, \mathrm{R}_{\mathrm{W} \_} \mathrm{AvR}_{\mathrm{TG}}$ and \# $\mathrm{R}_{\mathrm{F}}$ measures using WM rule bases for MAX ACC point.

\begin{tabular}{cccc}
\hline Algorithm & $\begin{array}{c}\text { Ranking on MSE } \\
\text { (p-fried: } 0,000196)\end{array}$ & $\begin{array}{c}\text { Ranking } \mathrm{R}_{\mathrm{W}} \mathrm{AvR}_{\mathrm{TG}}(\mathrm{p}- \\
\text { friedn:0,000006) }\end{array}$ & $\begin{array}{c}\text { Ranking on } \mathrm{R}_{\mathrm{F}} \\
\text { (p-fried: 0,125315) }\end{array}$ \\
\hline MO-AD $_{\mathrm{I}(0.1-0.9)}$ & 1.1538 & 3 & 2.4615 \\
$\mathrm{MO}_{-} \mathrm{AD}_{\mathrm{I}(0.2-0.8)}$ & 2.0769 & 1.9231 & 1.7692 \\
$\mathrm{MO}_{\mathrm{AD}} \mathrm{AD}_{\mathrm{I}(0.3-0.7)}$ & 2.7692 & 1.0769 & 1.7692 \\
\hline
\end{tabular}

Table A.2 Rankings obtained through Friedman's test for different values of thresholds on $\mathrm{MSE}_{\mathrm{TST}}, \mathrm{R}_{\mathrm{W}_{-}} \mathrm{AvR}_{\mathrm{TG}}$ and \# $\mathrm{R}_{\mathrm{F}}$ measures using FS_MOGUL rule bases for MAX ACC point.

\begin{tabular}{lccc}
\hline Algorithm & $\begin{array}{c}\text { Ranking on MSE } \\
\text { (p-fried: } 0,0000091)\end{array}$ & $\begin{array}{c}\text { Ranking } \mathrm{R}_{\mathrm{W}} \mathrm{AvR}_{\mathrm{TG}} \\
\text { (p-fried: } 0,000002)\end{array}$ & $\begin{array}{l}\text { Ranking on } \mathrm{R}_{\mathrm{F}} \\
(\mathrm{p} \text {-fried: } 0,001366)\end{array}$ \\
\hline MO-AD $_{\mathrm{I}(0.1-0.9)}$ & 1.1538 & 3 & 2.8077 \\
MO-AD $_{\mathrm{I}(0.2-0.8)}$ & 2 & 2 & 1.7308 \\
MO-AD & 2.8462 & 1 & 1.4615 \\
\hline
\end{tabular}

Table A.3 Rankings obtained through Friedman's test for different values of thresholds on $\mathrm{MSE}_{\mathrm{TST}}, \mathrm{R}_{\mathrm{W}_{-}} \mathrm{AvR}_{\mathrm{TG}}$ and \# $\mathrm{R}_{\mathrm{F}}$ measures using WM rule bases for MAX INT point.

\begin{tabular}{lccc}
\hline Algorithm & $\begin{array}{c}\text { Ranking on MSE } \\
\text { (p-fried: } 0,000004)\end{array}$ & $\begin{array}{l}\text { Ranking } \mathrm{R}_{\mathrm{W}} \mathrm{AvR}_{\mathrm{TG}} \\
\text { (p-fried: } 0,000004)\end{array}$ & $\begin{array}{c}\text { Ranking on } \mathrm{R}_{\mathrm{F}} \\
\text { (p-fried: } 0,000004)\end{array}$ \\
\hline MO-AD $\mathrm{AD}_{\mathrm{I}(0.1-0.9)}$ & 1 & 3 & 3 \\
$\mathrm{MO}_{\mathrm{AD}}$ & 2.0385 & 1.9615 & 1.9615 \\
$\mathrm{MO}_{\mathrm{I}(0.2-0.8)}$ & 2.9615 & 1.0385 & 1.0385 \\
\hline
\end{tabular}


Table A.4 Rankings obtained through Friedman's test for different values of thresholds on MSE $\mathrm{TST}_{\text {, }} \mathrm{R}_{\mathrm{W} \_} \mathrm{AvR}_{\mathrm{TG}}$ and \#R measures using FS_MOGUL rule bases for MAX INT point.

\begin{tabular}{lccc}
\hline Algorithm & $\begin{array}{c}\text { Ranking on MSE } \\
\text { (p-fried: } 0,000912)\end{array}$ & $\begin{array}{c}\text { Ranking } \mathrm{R}_{\mathrm{W}} \mathrm{AvR}_{\mathrm{TG}} \\
\text { (p-fried: } 0,000002)\end{array}$ & $\begin{array}{c}\text { Ranking on } \mathrm{R}_{\mathrm{F}} \\
\text { (p-fried: 0,000012) }\end{array}$ \\
\hline MO-AD $_{\mathrm{I}(0.1-0.9)}$ & 1.3077 & 3 & 3 \\
MO-AD $_{\mathrm{I}(0.2-0.8)}$ & 1.9231 & 2 & 1.8462 \\
MO-AD $_{\mathrm{I}(0.3-0.7)}$ & 2.7692 & 1 & 1.1538 \\
\hline
\end{tabular}

Table A.5 Rankings obtained through Friedman's test for different values of thresholds on MSE $\mathrm{TST}_{2}, \mathrm{R}_{\mathrm{W} \_} \mathrm{AvR}_{\mathrm{TG}}$ and \# $\mathrm{R}_{\mathrm{F}}$ measures using WM rule bases for MEDIAN INT/ACC point.

\begin{tabular}{|c|c|c|c|}
\hline Algorithm & $\begin{array}{l}\text { Ranking on MSE }{ }_{\text {TST }} \\
\text { (p-fried: } 0,000002 \text { ) }\end{array}$ & $\begin{array}{l}\text { Ranking } \mathrm{R}_{\mathrm{W} \_} \mathrm{AvR} \mathrm{R}_{\mathrm{TG}} \\
\text { (p-fried: } 0,000002 \text { ) }\end{array}$ & $\begin{array}{l}\text { Ranking on } \mathrm{R}_{\mathrm{F}} \\
\text { (p-fried: } 0,000002 \text { ) }\end{array}$ \\
\hline MO-AD ${ }_{\mathrm{I}(0.1-0.9)}$ & 1 & 3 & 3 \\
\hline MO-AD $\mathrm{I}_{\mathrm{I}(0.2-0.8)}$ & 2 & 2 & 2 \\
\hline MO-AD $\mathrm{I}_{(0.3-0.7)}$ & 3 & 1 & 1 \\
\hline
\end{tabular}

Table A.6 Rankings obtained through Friedman's test for different values of thresholds on MSE $\mathrm{TST}_{\mathrm{T}}, \mathrm{R}_{\mathrm{W}_{-}} \mathrm{AvR}_{\mathrm{TG}}$ and $\# \mathrm{R}_{\mathrm{F}}$ measures using FS_MOGUL rule bases MEDIAN INT/ACC point.

\begin{tabular}{lccc}
\hline Algorithm & $\begin{array}{c}\text { Ranking on MSE } \\
\text { (p-fried: } 0,000006)\end{array}$ & $\begin{array}{c}\text { Ranking } \mathrm{R}_{\mathrm{W}} \mathrm{AvR}_{\mathrm{TG}} \\
\text { (p-fried: } 0,000002)\end{array}$ & $\begin{array}{l}\text { Ranking on } \mathrm{R}_{\mathrm{F}} \\
\text { (p-fried: 0,000002) }\end{array}$ \\
\hline MO-AD $_{\mathrm{I}(0.1-0.9)}$ & 1.0769 & 3 & 3 \\
MO-AD $_{\mathrm{I}(0.2-0.8)}$ & 1.9231 & 2 & 2 \\
MO-AD $_{\mathrm{I}(0.3-0.7)}$ & 3 & 1 & 1 \\
\hline
\end{tabular}

Table A.7 Finner Table with $\alpha=0.05$ for the methods on $\mathrm{MSE}_{\mathrm{TST}}, \mathrm{R}_{\mathrm{W}} \mathrm{AvR}_{\mathrm{TG}}$ and $\# \mathrm{R}_{\mathrm{F}}$ on MAX ACC point using WM rule bases.

\begin{tabular}{|c|c|c|c|c|c|c|c|c|c|c|c|}
\hline \multicolumn{4}{|c|}{$\mathrm{MSE}_{\mathrm{TST}}$} & \multicolumn{4}{|c|}{$\mathrm{R}_{\mathrm{W}} \quad \mathrm{AvR}_{\mathrm{TG}}$} & \multicolumn{4}{|c|}{$\# \mathrm{R}_{\mathrm{F}}$} \\
\hline $\mathrm{i}$ & Algorithm & $\mathrm{p}$-finner & Hypot & $\mathrm{i}$ & Algorithm & p-finner & Hypot & $\mathrm{i}$ & Algorithm & p-finner & Hypot \\
\hline 1 & MO-AD ${ }_{\mathrm{I}(0.3-0.7)}$ & 0.000076 & Rejec. & 1 & $\mathrm{MO}-\mathrm{AD}_{\mathrm{I}(0.1-0.9)}$ & 0.000002 & Rejec. & 1 & $\mathrm{MO}-\mathrm{AD}_{\mathrm{I}(0.1-0.9)}$ & 0.149097 & Accep. \\
\hline 2 & MO-AD $\mathrm{I}_{\mathrm{I}(0.2-0.8)}$ & 0.018603 & Rejec. & 2 & MO-AD $\mathrm{AD}_{\mathrm{I}(0.2-0.8)}$ & 0.030984 & Rejec. & 2 & MO-AD $\mathrm{AD}_{\mathrm{I}(0.2-0.8)}$ & 1 & Accep. \\
\hline
\end{tabular}

Table A.8 Finner Table with $\alpha=0.05$ for the methods on MSE $\mathrm{TST}_{\mathrm{T}}, \mathrm{R}_{\mathrm{W}_{-}} \mathrm{AvR}_{\mathrm{TG}}$ and $\# \mathrm{R}_{\mathrm{F}}$ measures on MAX ACC point using FS_MOGUL rule bases

\begin{tabular}{|c|c|c|c|c|c|c|c|c|c|c|c|}
\hline \multicolumn{4}{|c|}{$\mathrm{MSE}_{\mathrm{TST}}$} & \multicolumn{4}{|c|}{$\mathrm{R}_{\mathrm{W}} \mathrm{AvR}_{\mathrm{TG}}$} & \multicolumn{4}{|c|}{$\# \mathrm{R}_{\mathrm{F}}$} \\
\hline $\mathrm{i}$ & Algorithm & p-finner & Hypot & $\mathrm{i}$ & Algorithm & $\mathrm{p}$-finner & Hypot & $\mathrm{i}$ & Algorithm & p-finner & Hypot \\
\hline 1 & $\mathrm{MO}-\mathrm{AD}_{\mathrm{I}(0.3-0.7)}$ & 0.000032 & Rejec. & 1 & MO-AD $\mathrm{II}_{\mathrm{I}(0.1-0.9)}$ & 0.000001 & Rejec. & 1 & $\mathrm{MO}-\mathrm{AD}_{\mathrm{I}(0.1-0.9)}$ & 0.001179 & Rejec. \\
\hline 2 & MO-AD $\mathrm{AD}_{\mathrm{I}(0.2-0.8)}$ & 0.030984 & Rejec. & 2 & MO-AD $\mathrm{II}_{\mathrm{I}(0.2-0.8)}$ & 0.010187 & Rejec. & 2 & $\mathrm{MO}-\mathrm{AD}_{\mathrm{I}(0.2-0.8)}$ & 0.492457 & Accep. \\
\hline
\end{tabular}

Table A.9 Finner Table with $\alpha=0.05$ for the methods on $\mathrm{MSE}_{\mathrm{TST}}, \mathrm{R}_{\mathrm{W} \_} \mathrm{AvR}_{\mathrm{TG}}$ and $\# \mathrm{R}_{\mathrm{F}}$ measures on MAX INT point using $\mathrm{WM}$ rule bases

\begin{tabular}{|c|c|c|c|c|c|c|c|c|c|c|c|}
\hline \multicolumn{4}{|c|}{$\mathrm{MSE}_{\mathrm{TST}}$} & \multicolumn{4}{|c|}{$\mathrm{R}_{\mathrm{W} \_} \mathrm{AvR} \mathrm{R}_{\mathrm{TG}}$} & \multicolumn{4}{|c|}{$\# \mathrm{R}_{\mathrm{F}}$} \\
\hline $\mathrm{i}$ & Algorithm & $\mathrm{p}$-finner & Hypot & $\mathrm{i}$ & Algorithm & p-finner & Hypot & $\mathrm{i}$ & Algorithm & p-finner & Hypot \\
\hline 1 & MO-AD ${ }_{\mathrm{I}(0.3-0.7)}$ & 0.000001 & Rejec. & 1 & MO-AD ${ }_{\mathrm{I}(0.1-0.9)}$ & 0.000001 & Rejec. & 1 & MO-AD ${ }_{\mathrm{I}(0.1-0.9)}$ & 0.000001 & Rejec. \\
\hline 2 & MO-AD $\mathrm{A}_{\mathrm{I}(0.2-0.8)}$ & 0.008107 & Rejec. & 2 & MO-AD $\mathrm{I}_{\mathrm{I}(0.2-0.8)}$ & 0.018603 & Rejec. & 2 & MO-AD $\mathrm{I}_{\mathrm{I}(0.2-0.8)}$ & 0.018603 & Rejec. \\
\hline
\end{tabular}


Table A.10 Finner Table with $\alpha=0.05$ for the methods on $\mathrm{MSE}_{\mathrm{TST}}, \mathrm{R}_{\mathrm{W}} \mathrm{AvR}_{\mathrm{TG}}$ and $\# \mathrm{R}_{\mathrm{F}}$ measures on MAX INT point using FS_MOGUL rule bases

\begin{tabular}{|c|c|c|c|c|c|c|c|c|c|c|c|}
\hline \multicolumn{4}{|c|}{$\mathrm{MSE}_{\mathrm{TST}}$} & \multicolumn{4}{|c|}{$\mathrm{RW} / \mathrm{AvR} \mathrm{R}_{\mathrm{TG}}$} & \multicolumn{4}{|c|}{$\# \mathrm{R}_{\mathrm{F}}$} \\
\hline $\mathrm{i}$ & Algorithm & p-finner & Hypot & $\mathrm{i}$ & Algorithm & p-finner & Hypot & $\mathrm{i}$ & Algorithm & p-finner & Hypot \\
\hline 1 & MO-AD $\mathrm{I}_{\mathrm{I}(0.3-0.7)}$ & 0.000389 & Rejec. & 1 & MO-AD $\mathrm{I}_{\mathrm{I}(0.1-0.9)}$ & 0.000001 & Rejec. & 1 & MO-AD $\mathrm{I}_{\mathrm{I}(0.1-0.9)}$ & 0.000005 & Rejec. \\
\hline 2 & MO-AD $\mathrm{AD}_{\mathrm{I}(0.2-0.8)}$ & 0.116664 & Accep & 2 & MO-AD $\mathrm{AD}_{\mathrm{I}(0.2-0.8)}$ & 0.010187 & Rejec. & 2 & MO-AD $\mathrm{AD}_{\mathrm{I}(0.2-0.8)}$ & 0.047556 & Rejec. \\
\hline
\end{tabular}

Table A.11 Finner Table with $\alpha=0.05$ for the methods on $\mathrm{MSE}_{\mathrm{TST}}, \mathrm{R}_{\mathrm{W}} \mathrm{AvR}_{\mathrm{TG}}$ and $\# \mathrm{R}_{\mathrm{F}}$ measures on MEDIAN INT/ACC point using WM rule bases

\begin{tabular}{|c|c|c|c|c|c|c|c|c|c|c|c|}
\hline \multicolumn{4}{|c|}{$\mathrm{MSE}_{\mathrm{TST}}$} & \multicolumn{4}{|c|}{$\mathrm{RW} \quad \mathrm{AvR} \mathrm{R}_{\mathrm{TG}}$} & \multicolumn{4}{|c|}{$\# \mathrm{R}_{\mathrm{F}}$} \\
\hline $\mathrm{i}$ & Algorithm & p-finner & Hypot & $\mathrm{i}$ & Algorithm & p-finner & Hypot & $\mathrm{i}$ & Algorithm & p-finner & Hypot \\
\hline 1 & MO-AD $\mathrm{I}_{\mathrm{I}(0.3-0.7)}$ & 0.000001 & Rejec. & 1 & $\mathrm{MO}-\mathrm{AD}_{\mathrm{I}(0.1-0.9)}$ & 0.000001 & Rejec. & 1 & MO-AD $\mathrm{AD}_{\mathrm{I}(0.1-0.9)}$ & 0.000001 & Rejec. \\
\hline 2 & MO-AD $\mathrm{A}_{\mathrm{I}(0.2-0.8)}$ & 0.010187 & Rejec. & 2 & MO-AD $\mathrm{AD}_{\mathrm{I}(0.2-0.8)}$ & 0.010187 & Rejec. & 2 & MO-AD ${ }_{\mathrm{I}(0.2-0.8)}$ & 0.010787 & Rejec. \\
\hline
\end{tabular}

Table A.12 Finner Table with $\alpha=0.05$ for the methods on $\mathrm{MSE}_{\mathrm{TST}}, \mathrm{R}_{\mathrm{W}_{-}} \mathrm{AvR}_{\mathrm{TG}}$ and $\# \mathrm{R}_{\mathrm{F}}$ measures on MEDIAN INT/ACC point using FS_MOGUL rule bases

\begin{tabular}{|c|c|c|c|c|c|c|c|c|c|c|c|}
\hline \multicolumn{4}{|c|}{$\mathrm{MSE}_{\mathrm{TST}}$} & \multicolumn{4}{|c|}{ RW_AvR TG $_{\mathrm{TG}}$} & \multicolumn{4}{|c|}{$\# \mathrm{R}_{\mathrm{F}}$} \\
\hline $\mathrm{i}$ & Algorithm & p-finner & Hypot & $\mathrm{i}$ & Algorithm & p-finner & Hypot & $\mathrm{i}$ & Algorithm & p-finner & Hypot \\
\hline 1 & MO-AD ${ }_{\mathrm{I}(0.3-0.7)}$ & 0.000002 & Rejec. & 1 & MO-AD ${ }_{\mathrm{I}(0.1-0.9)}$ & 0.000001 & Rejec. & 1 & MO-AD ${ }_{\mathrm{I}(0.1-0.9)}$ & 0.000001 & Rejec. \\
\hline 2 & MO-AD $\mathrm{I}_{\mathrm{I}(0.2-0.8)}$ & 0.030984 & Rejec. & 2 & MO-AD $\mathrm{I}_{\mathrm{I}(0.2-0.8)}$ & 0.010187 & Rejec. & 2 & $\mathrm{MO}-\mathrm{AD}_{\mathrm{I}(0.2-0.8)}$ & 0.010787 & Rejec. \\
\hline
\end{tabular}




\section{Appendix B.}

Statistical analysis of the comparison between single-objective and multi-objective approaches.

Tables B.1 and B.2 show the rankings (through Friedman's test) for both WM and FS_MOGUL rule bases, respectively. The p-value computed using the
Friedman test implies that there are statistical differences among the results on $\mathrm{MSE}_{\mathrm{TST}}, \mathrm{R}_{\mathrm{W}} \mathrm{AvR}_{\mathrm{TG}}$, and $\# R_{F}$ respectively. In all cases $M O-A D_{I(0.1-0.9)}$ is the best in the ranking. In all cases, Finner test (Tables B.3, B.4 and B.5) rejects the null hypothesis with all singleobjective methods.

Table B.1 Rankings obtained through Friedman's test for different values of thresholds on $\mathrm{MSE}_{\mathrm{TST}}, \mathrm{R}_{\mathrm{W} \_} \mathrm{AvR}_{\mathrm{TG}}$ and \#R measures using WM rule bases

\begin{tabular}{lccc}
\hline Algorithm & $\begin{array}{l}\text { Ranking on MSE } \\
\text { (p-fried: 0,024914) }\end{array}$ & $\begin{array}{l}\text { Ranking on } \mathrm{R}_{\mathrm{W}-\mathrm{MR}} \mathrm{MR}_{\mathrm{TG}} \\
\text { (p-fried: 0,000002) }\end{array}$ & $\begin{array}{l}\text { Ranking on } \mathrm{R}_{\mathrm{F}} \\
\text { (p-fried: 0,000002) }\end{array}$ \\
\hline MO-AD $_{\mathrm{I}(0.1-0.9)}$ & 1.3846 & 1 & 1 \\
$\mathrm{SO}_{\mathrm{AD}}(0.1-0.9)$ & 2.3077 & 2 & 2 \\
$\mathrm{SO}-\mathrm{AD}$ & 2.3077 & 3 & 3 \\
\hline
\end{tabular}

Table B.2 Rankings obtained through Friedman's test for different values of thresholds on MSE $\mathrm{TST}_{\text {, }} \mathrm{R}_{\mathrm{W}_{-}} \mathrm{AvR}_{\mathrm{TG}}$ and \#R measures using FS_MOGUL rule bases

\begin{tabular}{lccc}
\hline Algorithm & $\begin{array}{l}\text { Ranking on MSE } \\
\text { (p-fried: } 0,000072)\end{array}$ & $\begin{array}{l}\text { Ranking on } \mathrm{R}_{\mathrm{W}} \mathrm{MR}_{\mathrm{TG}} \\
\text { (p-fried: 0,000002) }\end{array}$ & $\begin{array}{l}\text { Ranking on } \mathrm{R}_{\mathrm{F}} \\
\text { (p-fried: 0,000002) }\end{array}$ \\
\hline MO-AD $_{\mathrm{I}(0.1-0.9)}$ & 1.0769 & 1 & 1 \\
SO-AD $_{\mathrm{I}(0.1-0.9)}$ & 2.1538 & 2 & 2 \\
SO-AD & 2.7692 & 3 & 3 \\
\hline
\end{tabular}

Table B.3 Finner Table with $\alpha=0.05$ for the methods on MSE $E_{T S T}, R_{W_{-}} A v R_{T G}$ and $\# R_{F}$ measures on MAX ACC point using WM rule bases

\begin{tabular}{|c|c|c|c|c|c|c|c|c|c|c|c|}
\hline \multicolumn{4}{|c|}{$\mathrm{MSE}_{\mathrm{TST}}$} & \multicolumn{4}{|c|}{$\mathrm{R}_{\mathrm{W}} \mathrm{MR}_{\mathrm{TG}}$} & \multicolumn{4}{|c|}{$\# \mathrm{R}_{\mathrm{F}}$} \\
\hline $\mathrm{i}$ & Algorithm & p-finner & Hypot & $\mathrm{i}$ & Algorithm & $\mathrm{p}$-finner & Hypot & $\mathrm{i}$ & Algorithm & p-finner & Hypot \\
\hline 1 & SO-AD & 0.03686 & Rejec. & 1 & SO-AD & 0.000001 & Rejec. & 1 & SO-AD & 0.000001 & Rejec. \\
\hline 2 & SO-AD ${ }_{\mathrm{I}(0.1-0.9)}$ & 0.03686 & Rejec. & 2 & SO-AD ${ }_{\mathrm{I}(0.1-0.9)}$ & 0.010787 & Rejec. & 2 & SO-AD ${ }_{\mathrm{I}(0.1-0.9)}$ & 0.010787 & Rejec. \\
\hline
\end{tabular}

Table B.4 Finner Table with $\alpha=0.05$ for the methods on MSE $E_{T S T}, R_{W_{-}} A v R_{T G}$ and $\# R_{F}$ measures on MAX ACC point using FS_MOGUL rule bases

\begin{tabular}{cccccccccccc}
\multicolumn{1}{c}{ MSE $_{\mathrm{TST}}$} & \multicolumn{1}{c}{$\mathrm{R}_{\mathrm{W} \_} \mathrm{MR}_{\mathrm{TG}}$} & \multicolumn{4}{c}{ \#R $_{\mathrm{F}}$} \\
\hline $\mathrm{i}$ & Algorithm & $\mathrm{p}$-finner & Hypot & $\mathrm{i}$ & Algorithm & p-finner & Hypot & $\mathrm{i}$ & Algorithm & p-finner & Hypot \\
\hline 1 & $\mathrm{SO}-\mathrm{AD}$ & 0.000032 & Rejec. & 1 & $\mathrm{SO}-\mathrm{AD}$ & 0.000001 & Rejec. & 1 & $\mathrm{SO}-\mathrm{AD}$ & 0.000001 & Rejec. \\
2 & SO-AD $_{\mathrm{I}(0.1-0.9)}$ & 0.00604 & Rejec. & 2 & SO-AD $_{\mathrm{I}(0.1-0.9)}$ & 0.010787 & Rejec. & 2 & SO-AD $_{\mathrm{I}(0.1-0.9)}$ & 0.010787 & Rejec. \\
\hline
\end{tabular}

Table B.5 Finner Table with $\alpha=0.05$ for the methods on MSE $E_{T S T}, R_{W_{-}} A_{v} R_{T G}$ and $\# R_{F}$ measures on MAX ACC point using FS_MOGUL rule bases

\begin{tabular}{cccccccccccc}
\multicolumn{4}{c}{ MSE $_{\mathrm{TST}}$} & \multicolumn{1}{c}{$\mathrm{R}_{\mathrm{W}} \mathrm{MR}_{\mathrm{TG}}$} & \multicolumn{4}{c}{ \#R $_{\mathrm{F}}$} \\
\hline $\mathrm{i}$ & Algorithm & p-finner & Hypot & $\mathrm{i}$ & Algorithm & p-finner & Hypot & $\mathrm{i}$ & Algorithm & p-finner & Hypot \\
\hline 1 & $\mathrm{SO}-\mathrm{AD}$ & 0.000032 & Rejec. & 1 & SO-AD & 0.000001 & Rejec. & 1 & $\mathrm{SO}-\mathrm{AD}$ & 0.000001 & Rejec. \\
2 & $\mathrm{SO}_{\mathrm{AD}}(0.1-0.9)$ & 0.00604 & Rejec. & 2 & SO-AD $_{\mathrm{I}(0.1-0.9)}$ & 0.010787 & Rejec. & 2 & SO-AD $_{\mathrm{I}(0.1-0.9)}$ & 0.010787 & Rejec. \\
\hline
\end{tabular}

